\title{
Investigation into the effects of two immiscible fluids on coefficient of discharge during compartment flooding
}

\author{
X. Wang ${ }^{\text {a) }}$, A. Li $^{\text {a) }}$, A.J. Sobey), ${ }^{\text {a) }}$, and M. Tan ${ }^{\text {a) }}$

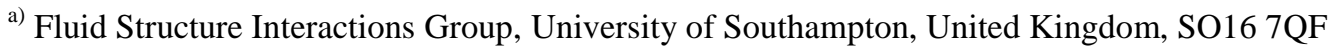

\begin{abstract}
Despite the best precautions accidents that result in damage occur. Whether these damages occur to ships, offshore platforms or risers there is the potential that the ruptured compartment contains oil. In these scenarios it is important to understand how the leaking fluids will behave for the safety of the structure and to reduce the severity of the damage to the environment. To investigate the severity of oil leakage during damage fluid flow, experiments have been conducted investigating the effects of the shape and size of the damage orifice on the coefficient of discharge. Testing was performed on test panels with 14 different orifices with no petalling and 15 with petalling. The flooding rate of oil leaking out of a compartment was then measured and orifice flow theory applied to obtain the value of the discharge coefficient. The experimental results are compared to results generated previously for water flowing into a damaged orifice for the same shape and area of orifice. Whilst the trends for the coefficient of discharge are similar, for interacting immiscible fluids the value for the coefficient of discharge is smaller than for water flooding into an empty compartment and the flow takes considerably longer to reach equilibrium.
\end{abstract}

Keywords: Compartment Flooding, Coefficient of Discharge, Damaged Structures, Oil Discharge

\section{Introduction}

Oil spills, resulting from accidents at sea, cause wide spread damage to marine environments. For example, Patrick (2010) reported the disaster of the tanker Torrey Canyon which spilled her entire cargo of about 120,000 tons of crude into the sea while entering the English Channel. This accident caused huge economic losses and adversely affected the environment for a significant period. Fingas (2001) reported that currently the average cost of worldwide oil clean-up ranges from $\$ 20$ to $\$ 200$ per

* Corresponding author. Tel.: +44 2380597773

Email address: ajs502@soton.ac.uk (A.J.Sobey) 
litre, depending on the oil type and its spill location; it is usually most expensive to clean up oil on shorelines.

During a damage scenario the time taken for the oil to drain from a vessel can change substantially depending on the environment and the size and shape of the damage. In these cases it is vital that the damage is limited and that the oil flowing rate can be quickly and easily calculated to ensure that minimal damage occurs. However, it is difficult for responders to estimate the amount of leaking oil from the damaged structure during an emergency. In addition to damage from the oil flowing out from the damaged compartment the influx of water flooding into the compartment could pose a threat to ship stability and structural integrity. A simplified understanding of these phenomena could be used to provide guidance to crews in how to best react to damage scenarios and aid salvage.

A number of previous studies have investigated the behaviour of damaged vessels concentrating on the flooding of ferries. An early example is Spouge (1986) who found it only took minutes for rapid capsize after the collision occurred for transient asymmetric flooding. Further examples of research on Ro-Ro ships using time domain simulation methods were performed by Sen and Koustantinidis (1987), Dand (1988), Vassalos and Turan (1994), Journee et al. (1997), Zaraphonitis et al. (1997) and Chang and Blume (1998). These results show that simulation of the ship's flooding and capsizing time history is possible but the time requirements are inhibitive to emergency response usage.

To model damaged vessel, Turan and Vassalos (1994) proposed a modified calculating solution to simulate the flooding in ro-ro vessel, which applied Bernoulli's equation to volumetric flows under the condition of approximately constant flooding rate, rather than the traditional time dependent method, allowing for a decrease in calculation time. A comparison with experimental data was generated by Vassalos and Letizia (1998) to validate the performance of this solution. Verdeveldt and Journee (1991) and Xia et al. (1999) proposed a similar method using a hydraulic flow model together with a damaged vessel's dynamic roll motion. Verdeveldt and Journee(1991) focused on considering the degree-of-freedom to be quasi-stationary 
whereas Xia et al. (1999) considered compression of air and how to achieve a more reliable numerical result through the artificial damping in the hydraulic model. Apart from hydraulic models, there are other methods to simulate the flooding process. By applying the potential flow solution, Hearn et al (2008) calculated the relevant coefficients of floodwater to analyse flooding flow. Moreover, he considered the interaction between internal and external water. In addition to potential flow, Santos and Guedes Soares (2008) applied computational fluid dynamics with shallow water theory to their simulation. This method does not have the inaccuracies associated with hydraulic models when simulating flooding dynamics. A numerical tool was developed by Gao (2011) to simulate the flooding process on a Ro-Ro ferry based on the Navier-Stokes solver and the result was close to that of the corresponding experiment.

For an initial estimation of flooding rate, the coefficient of discharge, or $C_{d}$, is commonly used in practice. If the value of the $C_{d}$ is known, an assessment of a damage scenario can be made quickly. Some early experiment conducted by Smith and Walker (1923) found the coefficient of discharge varies from 0.67 for a $2 \mathrm{~cm}$ orifice to 0.614 for a $6 \mathrm{~cm}$ orifice with heads above $1.2 \mathrm{~m}$. Generating a range of coefficients of discharge, Ruponen et al. (2006, 2007, 2010) completed a series of experiments to measure the flooding rate of a box-shaped barge. These tests showed a fluctuation of between $0.72-0.83$ for the coefficient of discharge in different types of flooding scenarios such as broken pipes and staircases ranging from a $20 \mathrm{~mm} \times 20 \mathrm{~mm}$ to a $100 \mathrm{~mm} \times 100 \mathrm{~mm}$ damage size where the $C_{d}$ value decreases as the opening size increases. This trend was again shown by Smith (2009) and in his experiments, a hydraulic model was used to measure the discharge coefficient of different damage geometries. The model was forced at constant vertical velocities and the discharge coefficient was calculated at each velocity. The results show a strong sensitivity to the orifice size and flow direction (ingress/egress) and less sensitivity to the velocity of the model. In addition, the jet velocity also decreased when the orifice size increased. Wood (2010) experimentally determined the $C_{d}$ values for 10 orifices with different shape and areas and compared the results with CFD simulation. The results show as the area getting smaller, the $C_{d}$ value decreases and that the shape can affect the $C_{d}$ value. Further research by Wood (2013) showed that the $C_{d}$ value was highly 
dependent on time during flooding process. $C_{d}$ values varied from 0.3 to over 1 depending on when the measurements were taken. In addition, mean transient flooding $C_{d}$ varied from 0.53 to 0.74 .

Recent research into flows involving damaged structures includes Eghtesad et al. (2012) who provided a review of a number of cases where damage has been investigated for a range of applications using different fluid modelling methods. Calyron et al. (2013) summarised the problems associated with modelling leakage through cracks in thin walled structures. Bazso and Hos (2013) highlighted the difficulties in estimating this coefficient of discharge finding that the current estimates were not suitable for their calculations for direct spring loaded poppet relief valves. $\mathrm{Li}$ et al. (2013) performed a systematic analysis of damaged orifices with petalling. The results show that both the bending angle and the integrity of petals have significant influence on the $C_{d}$ value. The increase in bending angle enlarges the $C_{d}$ value and the $C_{d}$ of inward facing petals is always greater than the ones outward facing for flooding cases.

In addition to these examples utilising only one fluid some analyses have also been performed combining oil and water. Karafiath (1992) and Karafiath and Bell (1992) performed model tests of oil outflow for mid-deck and double-hull tanker configurations. Simecek-Beatty et al (2001) used orimulsion, a bitumen based fuel, and canola oil to experimentally assess damaged holes above and below the waterline. The test results showed that the $C_{d}$ value for canola oil was 0.45 and for Orimulsion, was 0.48 . These values were smaller than the default $C_{d}$ value, 0.65 , in the ADIOS2 leaking tank model and the value concluded by Dodge et al. (1982) which indicated that a low $C_{d}$ value of 0.4 was expected for a low Reynolds number case. However, it is stated that the relatively thick tank walls, compared to the hole diameter, might lead to a small decrease in $C_{d}$ value. Tavakoli et al. (2008) investigated the theoretical outflow rate and spill volume based on Bernoulli's principle and extended in Tavakoli et al. (2009) for oil spills with the inclusion of hydrostatic changes. Finally Tavakoli et al. (2011) performed experimental testing of oil spills for practical applications using a mixture of vegetable and olive oil investigating different hull types and punctures above and below the waterline showing that hull type was an important 
factor for spill period. Mohammad et al. (2010) numerically and analytically investigated the oil spill from a side tank by modelling an oil tank with side collision damage. This study indicated that if the oil level in the oil tank is much higher than the outside water level, there will be two phases during the oil spill process. According to the numerical simulation performed the discharge coefficients are different in the two phases. The estimated value of discharge coefficient $C_{d}$ is 0.6 for the first phase and 0.45 in the second phase. Further similar studies have investigated oil and water flows through horizontal pipes such as Tan et al. (2014) and Balakhrisna et al. (2010) who discuss the difficulties in modelling multiphase flows of oil and water providing excellent reviews of the literature available focussing on more complex methods to measure and assess the flowrate.

Previous research has shown that there is a requirement to understand the flow of fluids through orifices for damaged cases at a fundamental level. Li et al. (2013) performed experiments that highlighted the change in coefficient of discharge between flat orifices and those containing more realistic petalled edges. However, this research has only so far considered a single fluid flowing though the orifice. Whilst research has been performed on oil spills at an applied level this paper aims to apply the experimental procedure developed in $\mathrm{Li}$ et al. (2013) to categorise fluid flows with immiscible fluids. This will allow guidance on the effects of oil on the coefficient of discharge in cases where there is an oil spill. Experiments will be performed for flat and petalled orifices by measuring the discharge rate of oil and water and calculating the discharge coefficient.

\section{Orifice Flow Theory}

Massey (1968) defines an orifice as: "an aperture through which fluid passes and its thickness (in direction of flow) is very small in comparison with its other measurements." Maritime structures are mostly made of steel plate which varies from $10 \mathrm{~mm}$ to $30 \mathrm{~mm}$ but where the total length is often greater than $100 \mathrm{~m}$. Therefore, oil spill accidents can be classified as an orifice flow problem. In practice, the actual flow rate through the orifice is often less than that of the ideal flow rate where the ratio of ideal discharge and actual discharge is defined as the coefficient of discharge, $C_{d}$. The 
$C_{d}$ value depends on the viscosity, turbulence and the geometry of orifice size, shape and petalling.

The earliest research of the orifice flow problem began with Torricelli (1643) who discovered that the relationship between the orifice flow velocity and hydrostatic pressure differential, between the two sides of the orifice, could be found by measuring the velocity of water flow through an orifice into the air and this can then be compared to the instantaneous hydrostatic head of water above the orifice. This relationship was later verified by Bernoulli (1738). Figure 1 illustrates Equation 1 which describes the relationship between the velocity through the orifice, $v$, and the hydrostatic head, h, and the gravity acceleration, g:

$v=\sqrt{2 g h}$

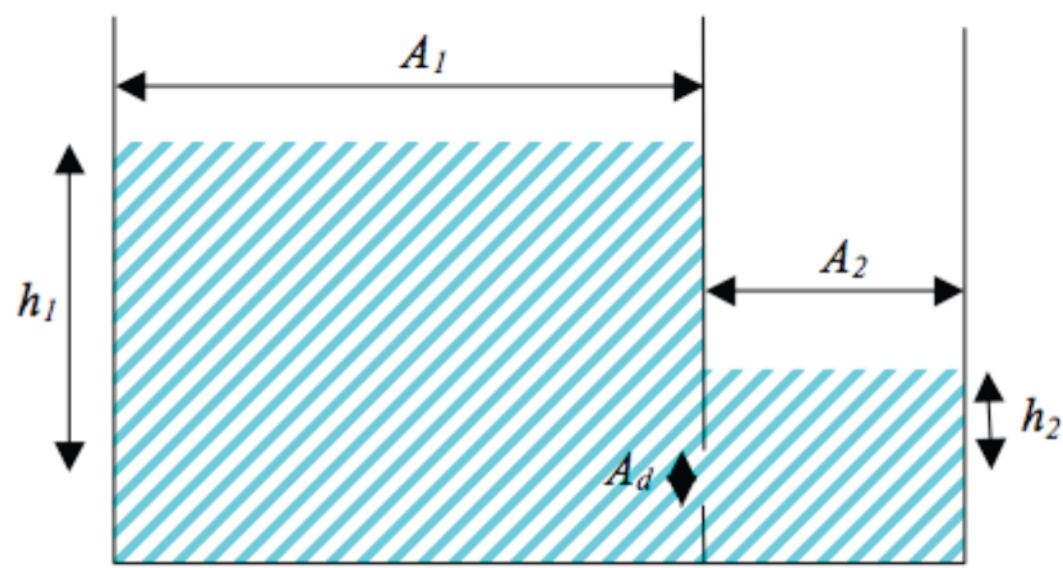

Figure 1 Dimensions for fluid flow through an orifice

To take into consideration of friction, viscosity and turbulence in orifice flow problems, namely to account for the differences between the basic ideal orifice flow theory and practical application to marine structures, Massey (1968) defined $C_{d}$ as the ratio of the actual discharge to the ideal discharge. The coefficient of discharge can be expressed by Equation 2 shown:

$C_{d}=\frac{\text { Actual discharge }}{\text { Ideal discharge }}$

Discharge coefficient can also be calculated using Equation 3: 
$C_{d}=C_{c} \times C_{v}$

where $C_{c}$ is the coefficient of contraction and $C_{v}$ is the coefficient of velocity.

According to the theory the flow remains parallel as the fluid flows though the orifice. In practice, frictional effects only produce parallel flow at a short distance from the orifice. The jet may converge, known as necking, and this can be taken into account using the coefficient of contraction which can be calculated using Equation 4:

$C_{c}=\mathrm{A} / \mathrm{A}_{\mathrm{d}} ;$

where $\mathrm{A}$ is the area of vena contracta, and $\mathrm{A}_{\mathrm{d}}$ is the area of the orifice. For an ideal circular or a sharp-edged orifice, the coefficient of contraction $C_{c}$ usually increases with the orifice diameter and as the head above the orifice decreases.

Additionally, the actual velocity at the vena contracta is also less than the ideal velocity at the orifice. Hence, the coefficient of velocity, $C_{v}$, is defined, in Equation 5, as the ratio of the actual mean velocity at the vena contracta to the ideal velocity at the orifice, it can be calculated:

$C_{v}=\mathrm{V} / \mathrm{V}_{\mathrm{i}}$

where $\mathrm{V}$ is the actual mean velocity at the vena contracta, and $\mathrm{V}_{\mathrm{i}}$ is the ideal velocity at the orifice. According to Smith and Walker (1923), the coefficient of velocity varies from 0.95 to 0.99 for diameters of orifice between $2 \mathrm{~cm}$ and $6 \mathrm{~cm}$ with heads up to $30 \mathrm{~m}$, and it is relatively insensitive to head change compared with coefficient of contraction $C_{c}$.

When the oil level in the compartment is sufficiently higher than the water level outside, as shown in Figure 2, the oil pressure will be higher than the water pressure at the orifice and the oil will discharge from the compartment. The centre of the orifice is chosen as the reference line. 


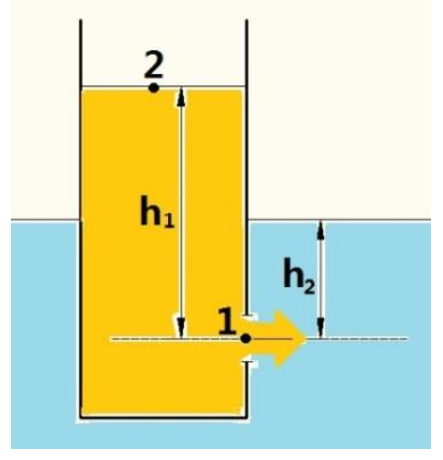

Figure 2 Oil flow with initial oil level higher than water

From Bernoulli's equation, shown in Equation 6,

$p_{1}+\rho g z_{1}+\frac{1}{2} \rho v_{1}^{2}=p_{2}+\rho g z_{2}+\frac{1}{2} \rho v_{2}^{2}$,

applying the quasi-static flow assumption, for point 1 and point 2, results in Equation 7

$\rho_{2} g h_{2}+\frac{1}{2} \rho_{1} v_{1}^{2}=\rho_{1} g h_{1}$,

which can be rearranged to Equation 8 ,

$v_{1}=\sqrt{2 g\left(h_{1}-\frac{\rho_{2}}{\rho_{1}} h_{2}\right)}$.

Combining Equation 2 and Equation 8 gives the $C_{d}$ shown in Equation 9,

$C_{d}=-\frac{A_{1} \dot{h_{1}}}{A v_{1}}=-\frac{A_{1} \dot{h_{1}}}{A \sqrt{2 g\left(h_{1}-\frac{\rho_{2}}{\rho_{1}} h_{2}\right)}}$.

where, $A_{1}$ is the horizontal sectional area of the compartment, $h_{1}$, is the internal fluid level, which is the oil height, at the current time instance measured from the reference, $A$ is the area of the orifice, $\rho_{1}$ is the density of oil, $\rho_{2}$ is the density of water, $g$ is the gravitational acceleration and $h_{2}$ is the distance between the external water surface to reference line. Equation 9 can be integrated over the time of the experiments to give:

$C_{d}=\frac{1}{\alpha t} \sqrt{\frac{2 h_{2}}{g}}\left(\sqrt{\frac{h_{\text {init }}}{h_{2}}-\frac{\rho_{2}}{\rho_{1}}}-\sqrt{\frac{h_{\text {end }}}{h_{2}}-\frac{\rho_{2}}{\rho_{1}}}\right)$

where $\alpha=\frac{A}{A_{1}}, h_{\text {init }}$ is the height of the oil level at the beginning of the experiment, $h_{\text {end }}$ is the height at the end and $t$ is the time taken for the oil level to change from $h_{\text {init }}$ to $h_{\text {end. }}$ 
When the internal oil level is lower than the water level outside as is the case in Figure 3 the oil pressure will be lower than the water pressure.

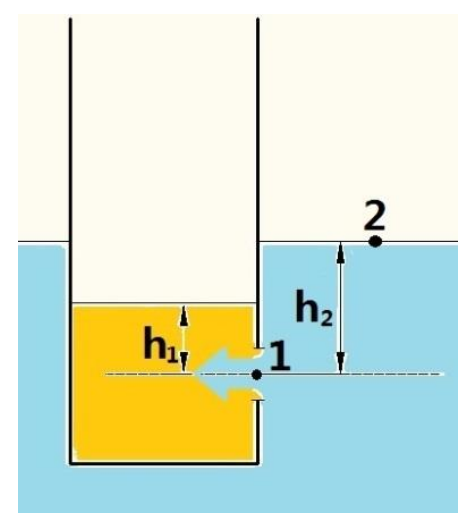

Figure 3 Flow of water when the oil level is below the water

In this case, the water floods into the compartment. Again, the orifice centre is chosen as the reference and the flow equations are similar and $C_{d}$ now takes the form in equation 11:

$C_{d}=\frac{1}{\alpha t} \sqrt{\frac{2 h_{2}}{g}} \sqrt{\frac{\rho_{2}}{\rho_{1}}}\left(\sqrt{\frac{\rho_{2}}{\rho_{1}}-\frac{h_{\text {init }}}{h_{2}}}-\sqrt{\frac{\rho_{2}}{\rho_{1}}-\frac{h_{\text {end }}}{h_{2}}}\right)$

These equations, 10 and 11, are used to calculate the $C_{d}$ in the results given below depending on the starting height of the oil within the container.

\section{Methodology}

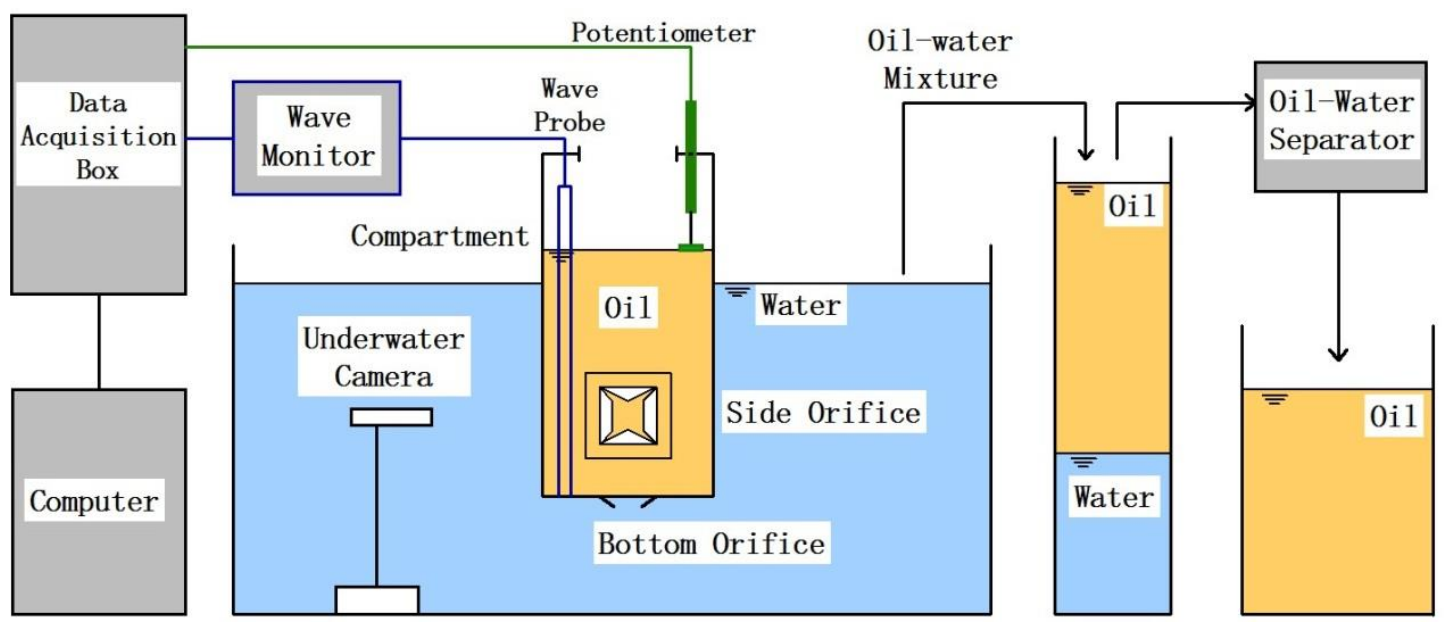

Figure 4 The general design of experiment 
To investigate the coefficient of discharge of oil and water a test rig was designed which is shown in Figure 4. A transparent acrylic compartment is placed into a larger tank of water. In order to achieve a similar scaling between the model and real application as Dodge et al. (1980) and Simecek-Beatty (2001), the scaling factor was chosen to be $1 / 16$. In this case, for a real compartment of about $10 \mathrm{~m}$ height, the height of the model compartment is set at $60 \mathrm{~cm}$. The inner size of the model compartment is designed to be $25 \mathrm{~cm} \times 25 \mathrm{~cm} \times 60 \mathrm{~cm}$ with a total volume of 37.5 litres. The distance between the centre of the orifice and the side of the compartment was therefore $12.5 \mathrm{~cm}$ and the distance from the edge of the orifice to the side of the compartment changed based on the damage area ranging from $911 \mathrm{~cm}$ to $\underline{119} \mathrm{~cm}$. The water tank selected in this project is an open top tank made of white rigid plastic to ensure that it did not change shape during the experiment. The diameter of the tank was chosen to be $110 \mathrm{~cm}$ and depth $70 \mathrm{~cm}$ to ensure: the oil layer stayed thin; the external water height did not change significantly, calculated to be $2.3 \mathrm{~cm}$ at most, and the flow did not interact with the side walls.

Before the test, the compartment is filled with oil and a plug is used to block the orifice. When the experiment starts, the plug is removed and the oil in the compartment spills out, or water flows in, through the orifice. A linear potentiometer is applied to measure the change of the oil level inside the compartment, Figure 5, and is installed vertically from the top plate of the compartment. The potentiometer consists of a main body, which is similar to a slide rheostat, a rod with a float and wire connecting to the power. The original float was not sensitive enough so it is redesigned by shaping foam so that it remains on the oil surface more accurately. When the oil level changes during the test, the foam plate will move and drive the free rod of the potentiometer and the resistance will change. This is connected to a voltmeter which is used to record the oil level every 0.1 seconds. A wave probe is used to measure the level of water and it consists of two parallel conductive iron wires which are fixed on the inner face of the side plate. The top side of the conductor is connected to the power and the voltage recorded with a voltmeter. As the wave probe is surrounded by oil, which is not a conductor, the probes were washed with washingup liquid before pouring the oil into the compartment. In order to obtain visual data of the experiment, an underwater camera is set in the water tank. The underwater camera is fixed on a microphone stand with a heavy iron base which can keep the camera 
stable in the water. After each test, the spilled oil, floating on the water surface, is collected and removed from the water tank.

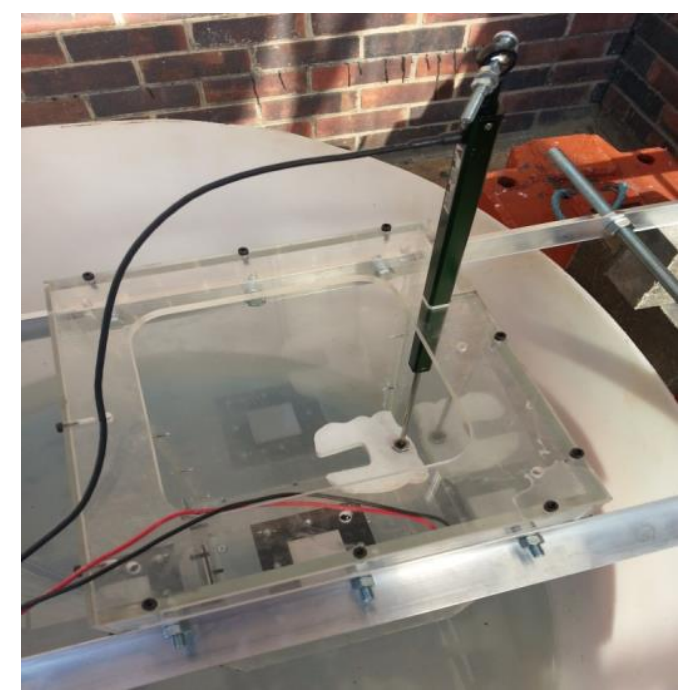

Figure 5 Potentiometer of the oil leaking experiment

Some assumptions have been made in the analysis of the flow including:

-The conditions, temperature, air pressure and fluid density, remain unchanged.

-At each time interval the fluid flow is assumed to be quasi-static.

-The thickness of the orifice is small compared to the size of the orifice.

-The external water free surface height is assumed to be constant.

-The time delay and disturbance generated when opening the 'plug' are ignored.

These assumptions, alongside the experimental equipment used, have resulted in errors within the experiments and these are outlines in Table 1 but the overall effects are considered small and the measured data are consistent between the runs. Previous experiments by the authors alongside comparisons with CFD using solely water have shown excellent repeatability with the first 4 seconds approximately showing divergence with a more settled and reliable flow after this point.

Table 1 Sources of error within the experiments

\begin{tabular}{|l|c|}
\hline Type of Error & \multicolumn{1}{c|}{ Source of Error } \\
\hline $\begin{array}{l}\text { Experiment } \\
\text { Setup }\end{array}$ & $\bullet \begin{array}{l}\text { There was some bending of the holding beam during the } \\
\text { experiment. }\end{array}$ \\
\hline
\end{tabular}




\begin{tabular}{|c|c|}
\hline & $\begin{array}{l}\text { - The compartment occasionally had a slight incline. } \\
\text { - The oil becomes less pure after some experiments. }\end{array}$ \\
\hline $\begin{array}{l}\text { Experiment } \\
\text { Procedure }\end{array}$ & $\begin{array}{l}\text { - The plug disturbs the motion around the orifice when } \\
\text { removed. } \\
\text { - The settling time is not long enough resulting in some water } \\
\text { inside the oil. } \\
\text { - The process of pouring the oil into the compartment also } \\
\text { adds water. }\end{array}$ \\
\hline $\begin{array}{l}\text { Recording } \\
\text { Methods }\end{array}$ & $\begin{array}{l}\text { - The potentiometer does not move smoothly causing some } \\
\text { fluctuations. } \\
\text { - Oil surrounds the wave probe reducing its conductivity. }\end{array}$ \\
\hline $\begin{array}{l}\text { Data } \\
\text { Processing }\end{array}$ & $\begin{array}{l}\text { - The above assumptions used to derive the Cd formula. } \\
\text { - Fitted data is used when data processing. }\end{array}$ \\
\hline
\end{tabular}

To achieve a similar Reynolds number for the model a significant change in the properties of the oil is required since the dimensions and the flow velocity of the experiment are much smaller than the damage orifice in a real ship. In SimecekBeatty et al.'s (2001) experiment, canola oil was applied to simulate heavy oils such as Boscan crude and Bunker C. Unfortunately, the density of canola oil is considerably less than water, which is not true for heavy oils, although the dynamic viscosity proved to be suitable after calculation. According to Simecek-Beatty et al. (1997), oil representing heavy oil should be 'considerably less viscous than a lowgravity oil (<20 API) and positively buoyant in both fresh- and salt water.' In their scale analysis, they found that canola oil, with a viscosity of $7.7 \times 10^{-3} \mathrm{Nsm}^{-2}$, was a good representative of oil with a viscosity of $0.5 \mathrm{Nsm}^{-2}$ at full-scale. They also suggested that canola would simulate petroleum products such as Boscan crude, Bunker C, and California heavy. Tavakoli et al. (2011) used olive oil having considered and then rejected vegetable oil. For the results presented here vegetable oil was chosen as its dynamic viscosity is relatively low and its density, 0.92, is within the range of crude oil density, 0.75-0.95, furthermore it is innocuous in a laboratory environment. Olive oil was added to the vegetable oil to darken the colour to make the higher contrast for the camera. 
Two different sets of experiments were performed using flat sided and petalled orifice plates shown in Figure 6 and Table 2 respectively. For the flat sided plates area and shape were varied to investigate the effect on the fluid flow. Four different shapes: square, circle, rectangle and pentacle, were used. The effects of area were investigated using: 4 circular shapes, with diameters of $69.81 \mathrm{~mm}, 55.85 \mathrm{~mm}, 51.52 \mathrm{~mm}$ and $30 \mathrm{~mm}$; 5 square shapes, with sides of $70 \mathrm{~mm}, 61.87 \mathrm{~mm}, 49.5 \mathrm{~mm}, 45.66 \mathrm{~mm}$ and $26.6 \mathrm{~mm}$; two rectangular shapes, with dimensions of $18.8 \mathrm{~mm} \times 37.6 \mathrm{~mm}$ and $13.29 \mathrm{~mm} \times 53.18 \mathrm{~mm}$, making aspect ratios of 1:2 and 1:4, and one pentacle shape, with radius $18.26 \mathrm{~mm}$. The area of these orifices was determined to allow comparison with Li et al. (2013) where petalled orifices were used.

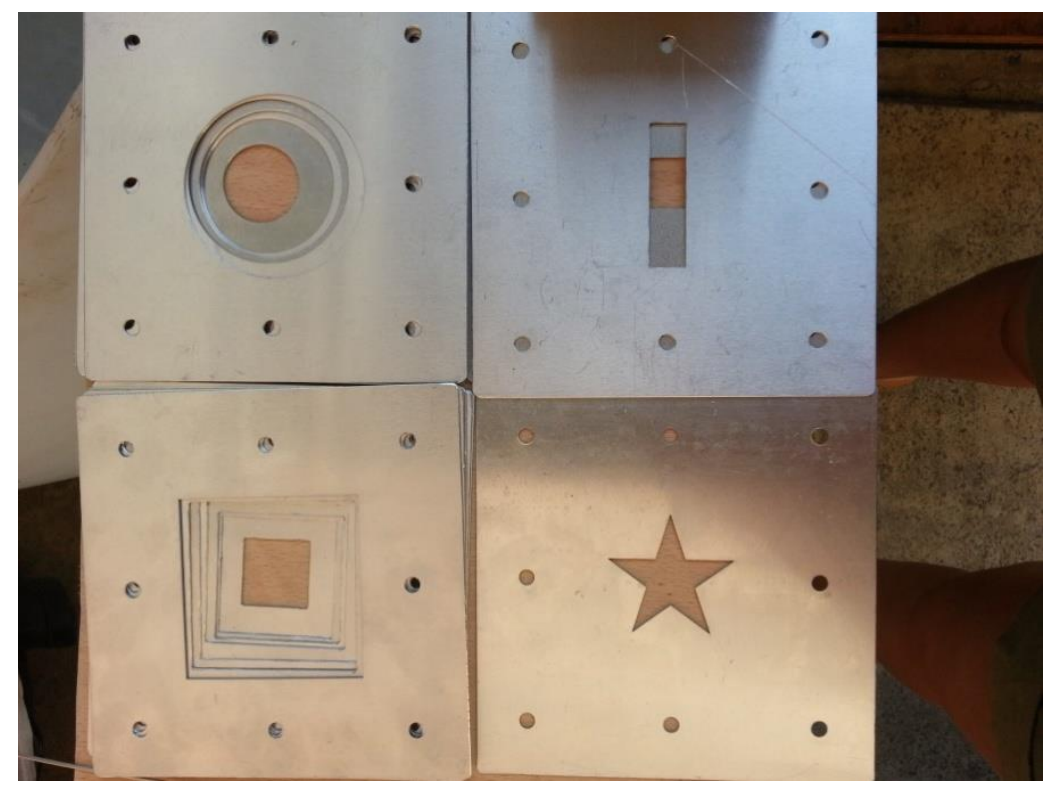

Figure 6 Different shapes for flat sided orifice flow experiment

For the petalled experiments three bending angles, $40^{\circ}, 60^{\circ}$ and $80^{\circ}$, were used to replicate a number of different conditions that can occur during damage scenarios and these were augmented with 3 integrity ratios: $25 \%, 50 \%$ and $100 \%$, defined by $\mathrm{Li}$ et al. (2013) as 'the ratio of the real acting petal's height and the full ideal petal's height'. The reason for choosing the height rather than the area of petal is that the relationship between $C_{d}$ and petal's height is more linear than the one between $C_{d}$ and the petal's area. To give a description to each of the experimental results a notation is used, adopted from Li et al. (2013), where the number refers to the degree of bending angle and the term following indicates the integrity ratio of the petals which can be uniform or a mix. For example, 40-Half means the orifice plate with $40^{\circ}$ bending angle and 
half, 50\%, integrity and 0-None means no petals. For clarity Table 2 shows all the orifice plates applied and their corresponding serial numbers.

All of the different orifice configurations were tested with the starting oil level higher than the water. For the case where the oil started lower than the water the circular, 69.81, 51.52 and 30, rectangular, 70 and 45.66, 60-Full, inward and outward, and 0None orifices were tested.

Table 2 Orifice plates and their serial numbers

(1)-Full

Coefficient of discharge has been calculated in all cases for the point at which the fluid volume had changed by $100 \mathrm{ml}$. The time period is determined based on this criterion and it was felt that a constant change in volume allowed an easier comparison between the different flooding scenarios. This is different from the calculations performed by Li et al. (2013) and it provided a more stable method by which to calculate the $C_{d}$ value for the interaction between immiscible fluids. The 
time period for the flow has been determined at the first time step, measured every 0.1 second, at which the final height is reached based on the fluid volume change.

\section{Verification}

To verify the experimental assumptions a comparison is made between the experiments and results Nie (2013) performed, using ANSYS FLUENT, 3D CFD analysis of the compartment under similar conditions where the problem was modelled as a 3 phase flow based on the volume of fluid approach. The density of the oil used is $920 \mathrm{kgm}^{-3}$ and its viscosity is $0.0346 \mathrm{Nsm}^{-2}$, where a sensitivity study was performed showing that this value had only a small influence on the flow period. In the simulations, in order to confirm the grid and time step size independency, a number of different grids and time step sizes were tested and the level of the relative difference in term of the oil volumes in the tank at specific time instances were around $0.02 \%$.

The final results obtained from the numerical modelling are compared with the experimental results in Figure 7 from the 0-None case to verify the results from the experimental equipment.

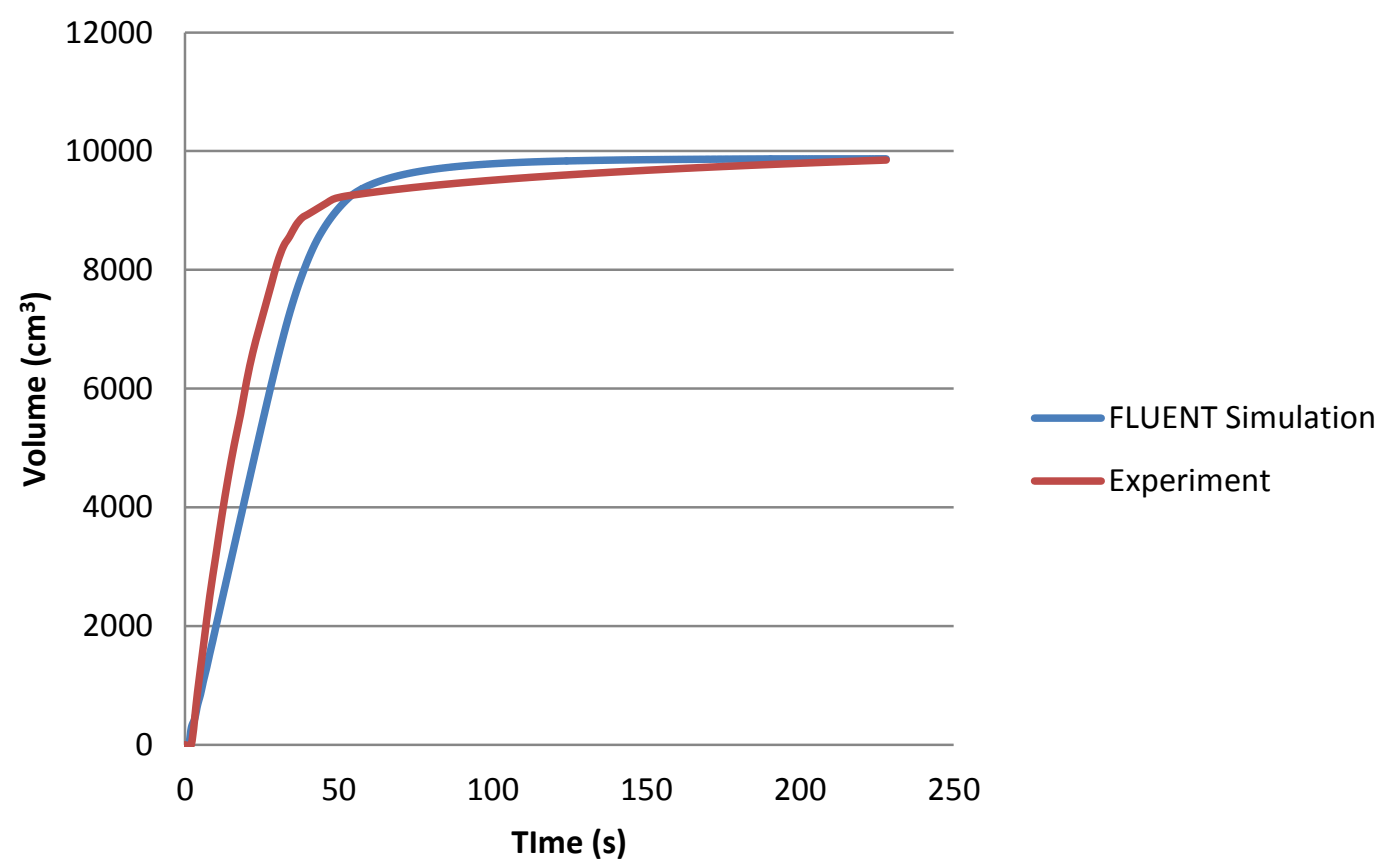

Figure 7 Verification of experimental flow rate by comparison with CFD 
Similar trends of water volume flooding into the compartment are shown at the beginning, where the water volume increases sharply. The experimental results show a faster initial rate which then slows rapidly when the compartment is almost full. The numerical results show a slower fill rate which continues to a larger volume. Potential reasons for the difference can be the differences in the fluid properties, namely oil density and viscosity, due to mixing sesame and vegetable oil and the geometry of the fluid domain in the experiments and CFD. However, the general trend of the experimental process is well replicated by CFD showing both the oil outflow and water exchange phases and that the effects of removal of the plug are minimal; examination of the results show that only approximately the first 4 secs of the flow are affected beyond which time the flows revert to a stable and predictable behaviour.

\section{Results for Oil Filled Compartment Flooding}

For clarity of the presentation, the results have been split into two sections. The first case covers the situation where the oil height is initially higher than the water outside of the compartment and the second case is where the oil is lower than the water height outside.

\subsection{Case 1 (Initial oil level higher than water level)}

Initially the oil pressure inside the compartment is higher than that outside and after a period of time, when the oil flows out into the water, the inner pressure balances with the outer pressure and then the leaking stops. Equilibrium is reached when the final level of oil in the compartment is just a little higher than that of water's due to the higher water density. This process is seen in the flow where an initial jet of oil, about $150 \mathrm{~mm}$ long in this experiment, shoots straight out into the water. After a few seconds this jet weakens and the oil flows straight towards the surface after which the oil stops leaking and the oil level remains stable. This process is depicted in Figure 8 for an orifice with full petalling facing outwards at $60^{\circ}$. 


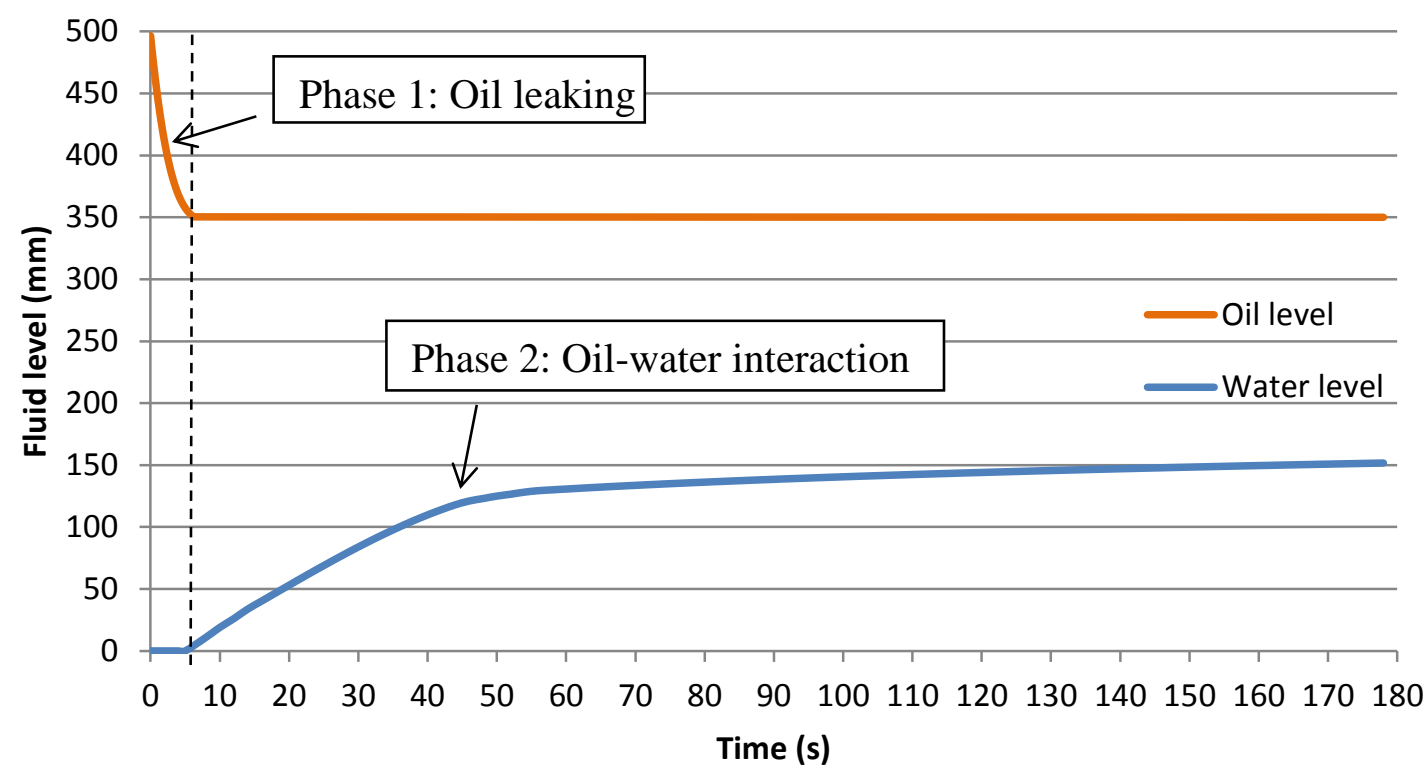

Figure 8 Oil and water levels with 60-Full outward facing orifice damage

This analysis has been split into damages with and without petalling and further separated within each of these categories between the two phases of the flow leaking and oil-water interaction.

\subsubsection{Flat sided orifices}

The jet of the flow from the container changed shape with each of the different orifices. The larger orifices gave a wider jet which was shorter and less stable on the boundaries of the jet.
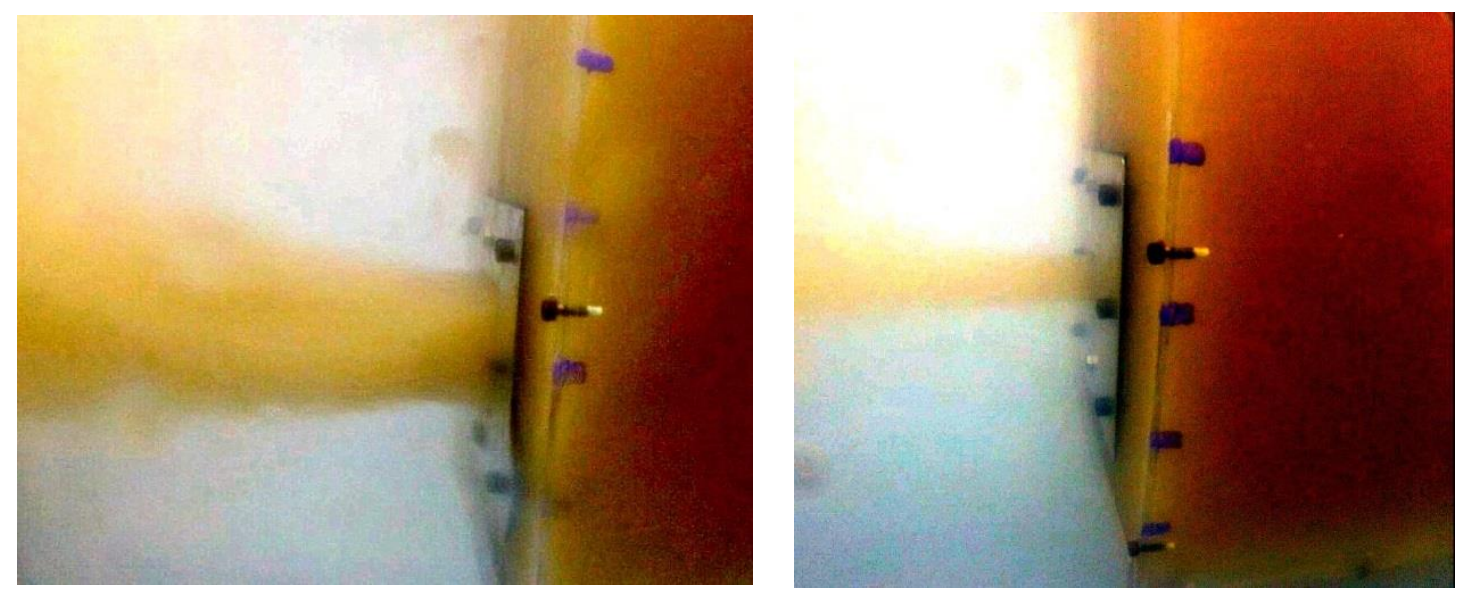
Figure 9: Oil jet for different orifices a) 0-None/Rectangle 70 b) Circle 30

In Figure 9a, oil is ejected from the compartment through the largest square orifice without any petals. The oil jet is strong and compact with the upper and lower border of the jet forming an almost straight line, though the jet is not completely stable. The $\mathrm{C}_{c}$ value for the flow is close to unity. At the end of the jet the oil starts to diverge and the upper and lower borders become less stable. The slight divergence at the jet end and the minor perturbation on the jet border indicate that this jet is becoming unstable. Figure $9 \mathrm{~b}$ shows a similar situation for the smaller circular orifice where the flow is more stable having a closer shape to the orifice and remaining stable for a longer distance.

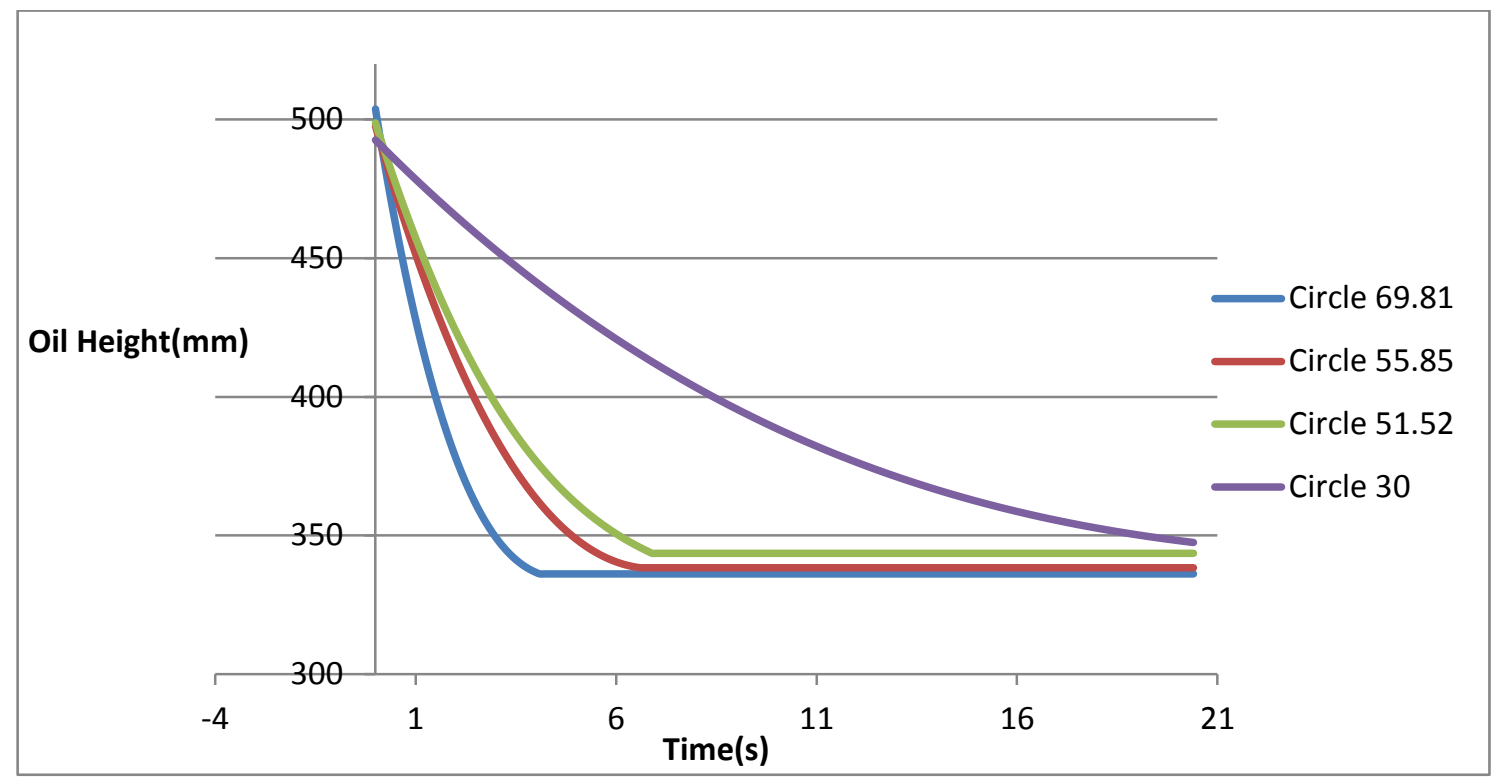

Figure 10 Change in oil height with circular orifice

Figure 10 shows the change in height over time for the four circular shaped damage scenarios with different diameters. A difference in the initial height of the oil can be seen of about $10 \mathrm{~mm}$ which is higher than expected and is, at least partly, due to the fact that it was measured by hand. The results show a similar trend for the largest three diameters with an initially fast rate of oil flow out of the compartment which slows to a point at which the height no longer changes. This stagnation height occurs at approximately the same level. The initial rate of flow is smaller as the damage size reduces and where the smallest diameter shape has a smoother change in height all the way to the final value. This same trend can also be shown for different sizes of 
rectangular orifices where different rates of change have been compared but the results are not presented here.

Table 3 Comparison of $C_{d}$ for different circular and square orifices

\begin{tabular}{|l|c|c|c|c|}
\hline Area & $3828.125 \mathrm{~mm}^{2}$ & $2450 \mathrm{~mm}^{2}$ & $2084.79 \mathrm{~mm}^{2}$ & $706.9 \mathrm{~mm}^{2}$ \\
\hline Square $C_{d}$ & 0.73 & 0.62 & 0.66 & 0.62 \\
\hline Circle $C_{d}$ & 0.71 & 0.64 & 0.65 & 0.61 \\
\hline Square Time Period (s) & 3.9 & 5.6 & 6.9 & 14.2 \\
\hline Circle Time Period (s) & 4.3 & 6.5 & 6.9 & 17.8 \\
\hline
\end{tabular}

Table 3 shows a comparison of the $C_{d}$ for circular and square orifices with different areas. It can be seen that the shape of the orifice makes little difference to the $C_{d}$ value at smaller areas and that the circle is generally a little lower than the rectangle. But for the $2^{\text {nd }}$ smallest area at $2084.79 \mathrm{~mm}^{2}$, the recorded time period is the same for both cases and it is not clear what the reason is but, it is likely this was due to experimental error since, although the square orifice would be expected to be larger than the circle. The largest orifice size has the largest $C_{d}$ value which is smaller for the other three orifice sizes which are approximately the same. For the flow rate there is a steady increase in the period of time for the flow to leave the container with the circle taking slightly longer than the rectangle for the same area.

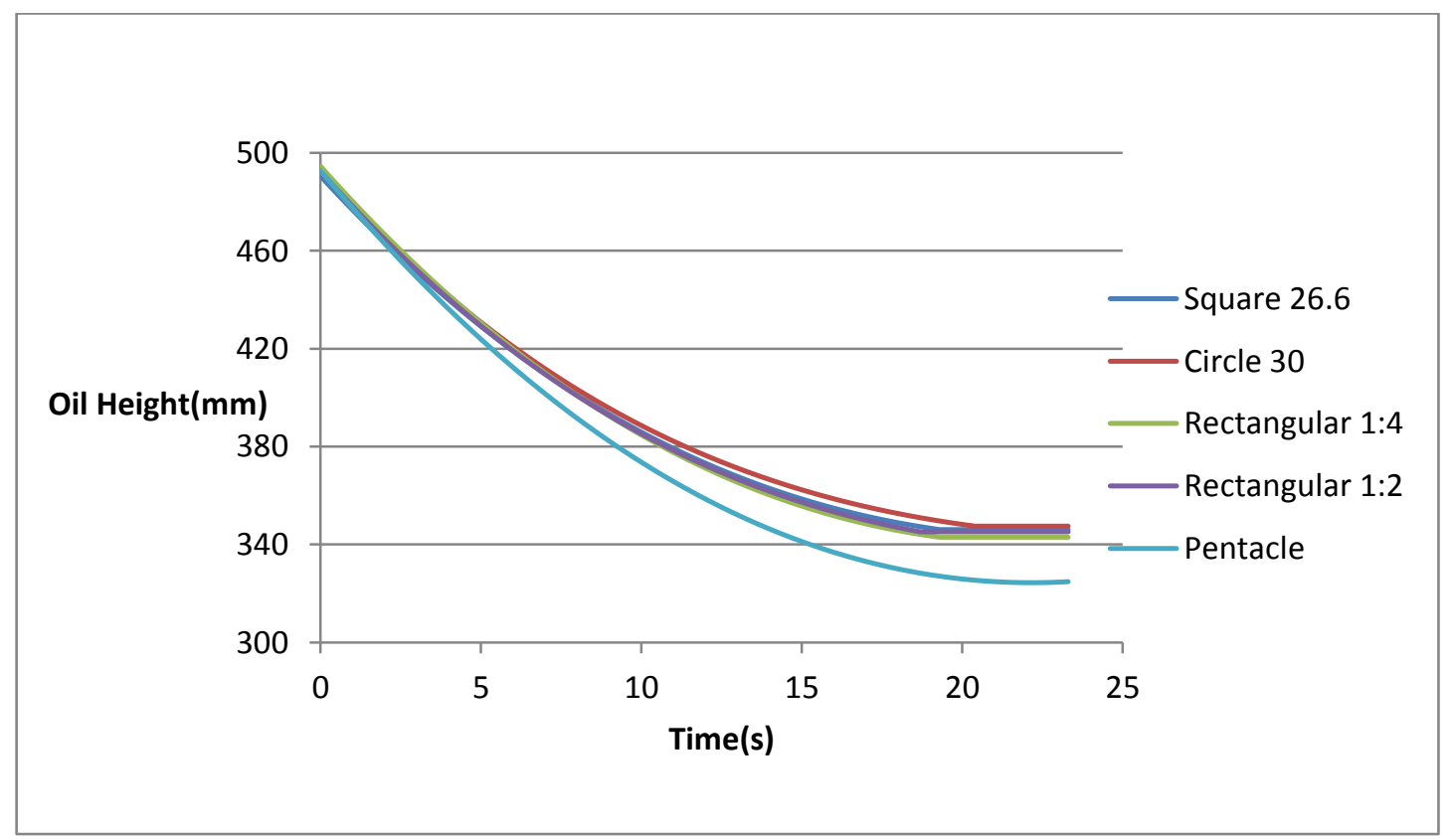

Figure 11 Comparison of leaking rate for differently shaped orifices 
In Figure 11, five different shaped orifices are compared with the same area of 706.9 $\mathrm{mm}^{2}$. The five shapes all have similar flow patterns to each other but the pentacle orifice has a faster flow rate than the others. The deceleration in rate of the pentacle shape happens most slowly and the final height of oil at the end is lower.

Table $4 C_{d}$ of different shaped orifices of $707 \mathrm{~mm}^{2}$ area

\begin{tabular}{|l|c|c|c|c|c|c|c|}
\hline Shape & Circle & Square & \multicolumn{2}{|c|}{ Rectangular } & \multicolumn{2}{|c|}{ Rectangular } & Pentacle \\
\hline $\begin{array}{l}\text { Defining } \\
\text { Dimension } \\
(\mathrm{mm})\end{array}$ & 30 & 26.6 & \multicolumn{2}{|c|}{$13.29 \times 53.18$} & \multicolumn{2}{|c|}{$18.8 \times 37.6$} & 18.26 \\
\hline Orientation & & & Vertical & Horizontal & Vertical & Horizontal & \\
\hline$C_{d}$ & 0.61 & 0.62 & 0.65 & 0.64 & 0.64 & 0.65 & 0.73 \\
\hline Time (s) & 17.8 & 14.2 & 18.6 & 15.3 & 19.2 & 20.5 & 22.3 \\
\hline
\end{tabular}

Comparing the $C_{d}$ for different orifice shapes in Table 4 it can be seen that the largest value is for the pentacle, which also has the longest time period for the oil leaking process, with the other shapes having a similar value to each other. The time for oil to finish flowing out was shortest for the square orifice. The flow time had a large range of between 14.2 and 22.3 seconds. For the outflow of oil, the orifice area has a minimal impact upon the coefficient of discharge and in general the shape has little effect except in the case of the pentacle.

Having investigated the oil flowing out of the compartment at some point, as water is denser than oil, the water will flow to the bottom of the compartment and the oil will remain on top. Once much of the oil has leaked out from the compartment an exchange occurs between the oil and water. 


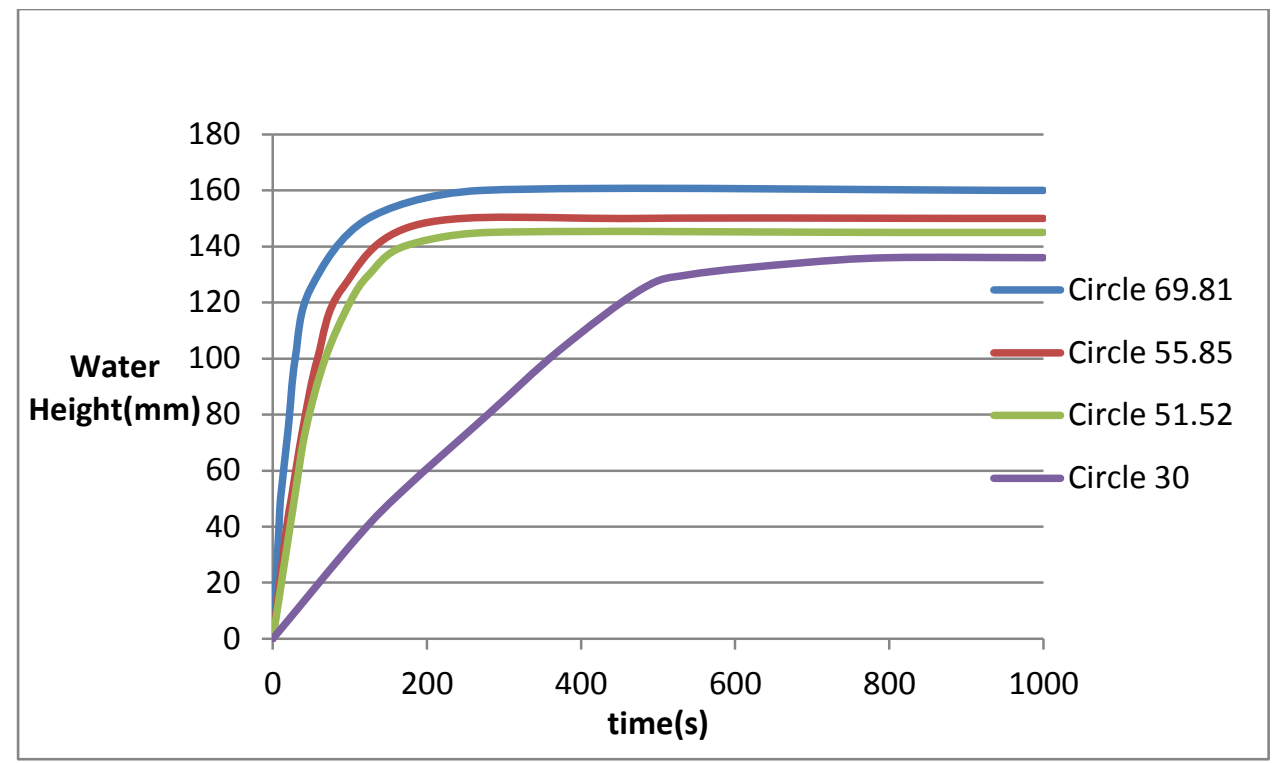

Figure 12 Oil-water exchanging of circle orifice

Figure 12 shows the exchange process for circular orifices with different areas. The results show a similar trend to the oil flowing out from the compartment and it is seen that a larger area of orifice results in a faster inflow of water. At the beginning, the rate of the rising water is rapid and then it slows before stopping at a fixed level where the system remains stable. The circle with the lowest area once again behaves a little differently with a considerably slower rate of flow. The highest water height is $160 \mathrm{~mm}$ and the lowest is $135 \mathrm{~mm}$ which correlate with the area of the orifice in these cases. A similar process is observed for the group with square orifices and therefore the results are not presented here.

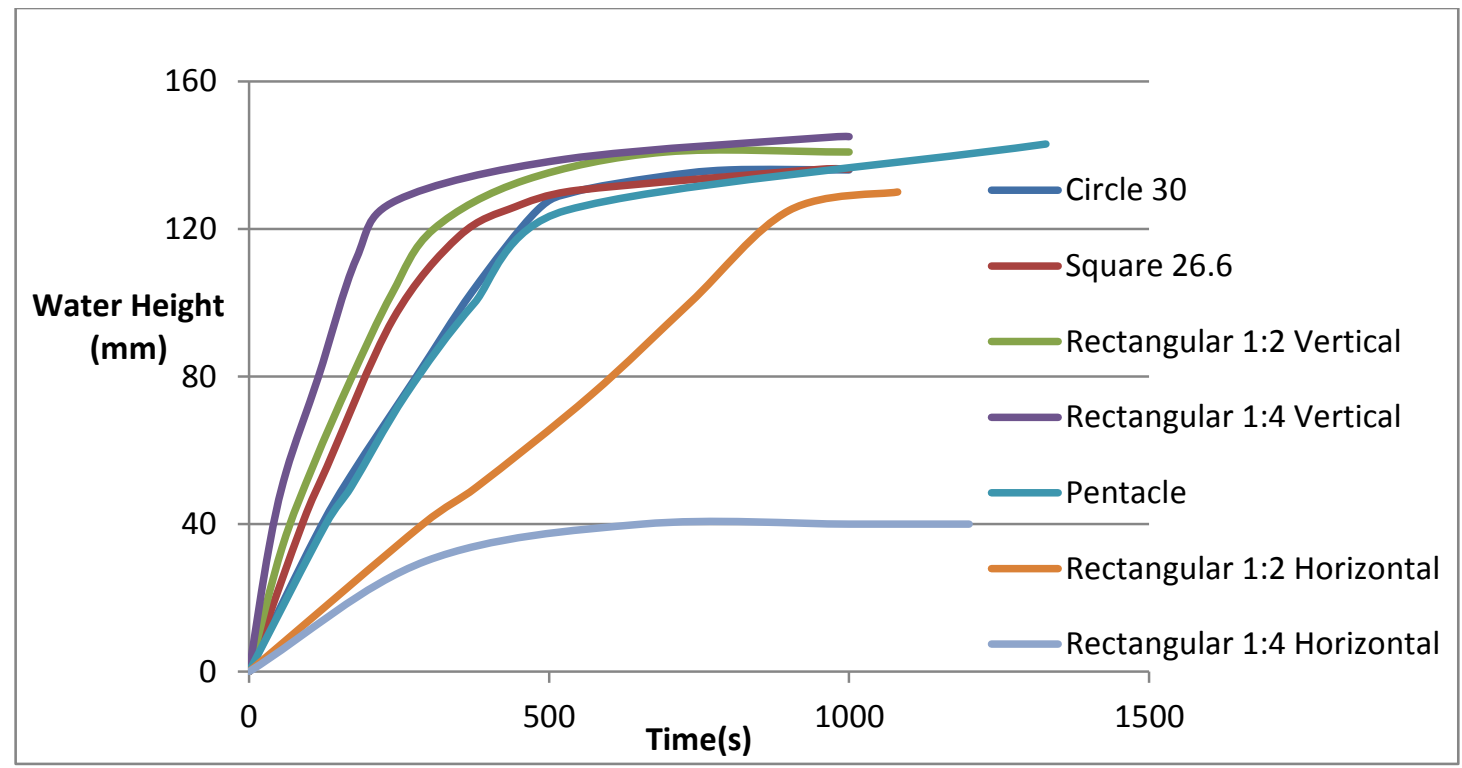


Figure 13 Oil-water exchanging with different shape orifices

Figure 13 shows the effect of changing the shape of the orifice on the water influx. The results show that the shapes behave in a similar manner to each other with a similar final height, except in the case where the rectangular shapes are horizontal. The results are less regular than those from the oil flowing out through the orifice or from water flooding into an empty compartment and the initial rate is lower. For the horizontally aligned rectangles the final water level in the compartment is different, both to each other and the rest of the shapes. The rectangle with 1:4 aspect ratio has the most dissimilar behaviour, represented by the lowest line highlighted in blue. These results show that the pressure difference between the higher and lower sides makes a large contribution to the water flowing into the compartment. When this difference is similar, as in the cases for the vertical rectangle, square, circle and star, the resulting flow is similar. For the case of the horizontal rectangle, where this dimension is much reduced, the flow changes considerably. When the orifice is too thin in the vertical direction, the pressure difference is too small and less water flows through the orifice.

\subsubsection{Petalled orifices}

A more realistic scenario, than a flat sided regular shape, for an orifice caused by damage is that it exhibits petalling. These petalled orifices have material at different angles, with different integrities of material projected into the flow. The change in direction of the orifice can have a large impact on this flow as can be seen in Figure 14. 


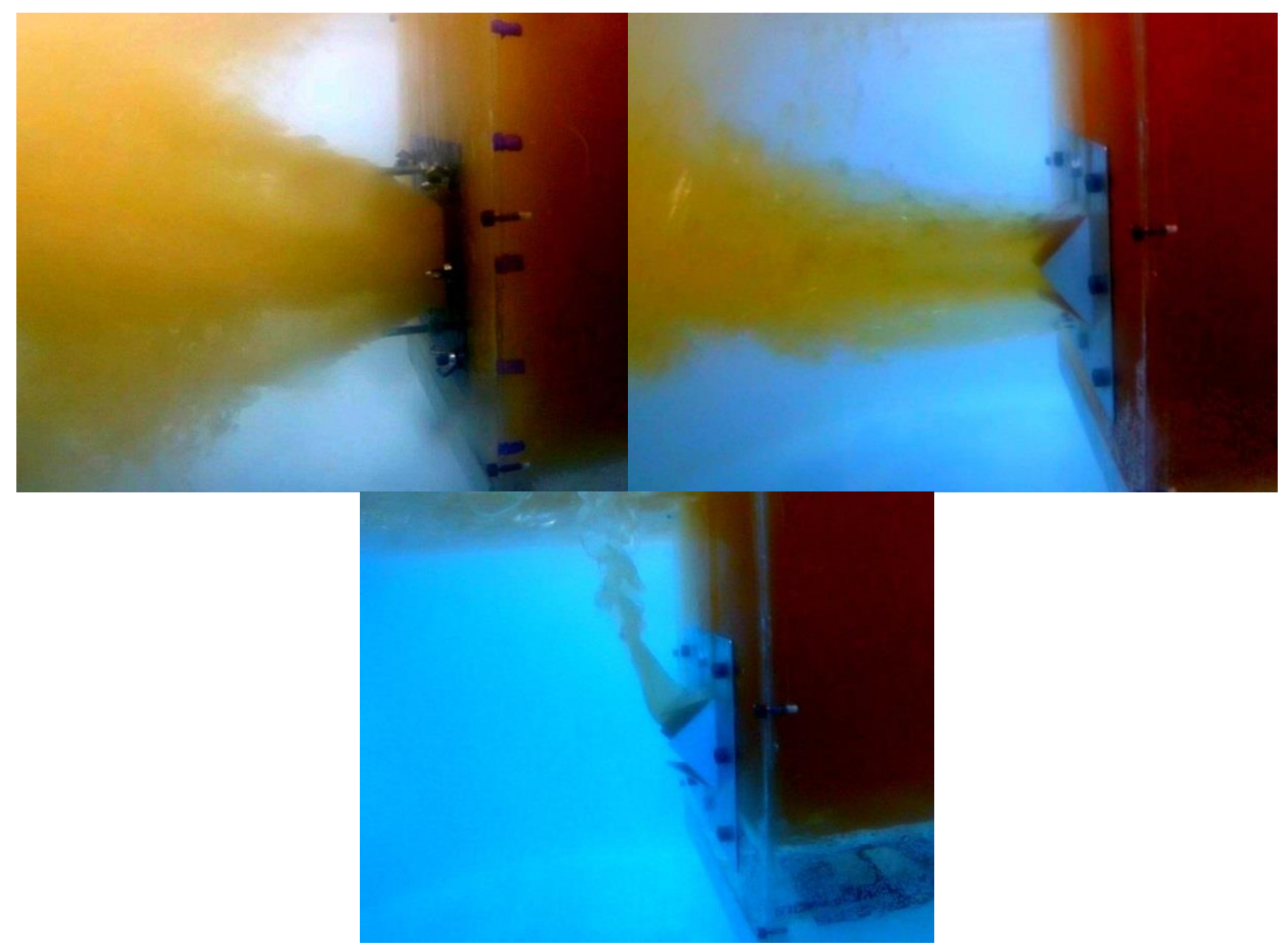

Figure 14 Oil jet for a) ' $60^{\circ}$-Full inward' b) ' $60^{\circ}$-Full outward' c) Water inflow

Figure 14a shows the oil jet with 60 -Full inward facing petals. This oil jet diverges from the edge of the orifice from the start of the flow to the end of the jet; although there is still a thin, concentrated and straighter jet in the centre as the inward facing petals serve as a guide. The upper and lower border of the jet is asymmetric and unstable. This is because the petals block the oil flow and the velocity of jet is reduced which makes it more likely to become weak and unstable. For the 60-Full outward facing petals the oil jet is less disturbed by the petals as shown in Figure 14b. The jet is thinner, more symmetric and stronger since the upper and lower borders of the central thin jet are quite smooth and intact. This results in a $\mathrm{C}_{c}$ that is closer to unity and therefore there is a resulting high $\mathrm{C}_{d}$ value.

Table 5 Spill period and $C_{d}$ for all petalled tests (Case 1)

\begin{tabular}{|l|l|l|l|l|}
\hline Petal No. & Spill period (s) & $C_{d}$ & Spill period (s) & $C_{d}$ \\
\hline
\end{tabular}




\begin{tabular}{|l|c|c|c|c|}
\hline & \multicolumn{2}{|c|}{ Inward Facing } & \multicolumn{2}{c|}{ Outward Facing } \\
\hline 0-None & 2.8 & 0.68 & 2.8 & 0.68 \\
\hline 40-Full & 10.2 & 0.67 & 9.8 & 0.73 \\
\hline 60-Full & 5.8 & 0.70 & 5.2 & 0.74 \\
\hline 80-Full & 3.9 & 0.62 & 3.4 & 0.79 \\
\hline 40-Half & 7.9 & 0.59 & 7.2 & 0.70 \\
\hline 60-Half & 4.6 & 0.60 & 3.8 & 0.83 \\
\hline 80-Half & 3.6 & 0.60 & 3.4 & 0.80 \\
\hline 60-Quarter & 4.2 & 0.60 & 3.5 & 0.78 \\
\hline \hline
\end{tabular}

Table 5 shows the $C_{d}$ and flooding period values of different petal bending angles and integrity ratios for an area calculated based on the projected area from the petals as performed in Li et al. (2013). It can be observed that the $C_{d}$ value decreases with decreasing bending angle, decreasing integrity and inward facing petals down to a minimum value of about 0.6 . For the bending angle this is because the petal around the orifice accelerates the flow through the petalling area. This ensures the flow leaves the orifice in the same shape as the orifice and it travels a reasonable distance before the flow separates, thus reducing the $C_{d}$ value. The effect of this acceleration are smaller with smaller bending angle. In addition, the $C_{d}$ values tested with petals straddle the test cases without, 0-None. This behaviour is the same as the observations made by Li et al. (2013) that the petals with high bending angle enhance the flow rate. The results also show that high integrity ratios can strengthen the effect of bending angle. There appears to be an anomaly in the results for the $80^{\circ}$ full petalled results where the flow is the fastest but the $\mathrm{Cd}$ value is lower than for the other values.

In Table 5, all the $\mathrm{C}_{d}$ values for the outward facing petals are larger than the corresponding inward facing ones. The reason is the change of the flow around the orifice as shown in Figure 15, where the jet diameter is represented by dotted lines. In the case of the outward facing petals, Figure 15a, the petals perform like a 'hopper' allowing the flow to be funnelled out of the orifice and forming a linear flow. This means that the value for $\mathrm{C}_{c}$ remains high as the area is similar between the projected area and the vena contracta. For the inward facing flow, Figure 15b, the oil passes through the orifice the flow is channelled towards the centre before separating back 
out. The inward facing petals separate the oil flow creating some turbulent flow creating a slower flow whilst reducing the $\mathrm{C}_{c}$ value and creating a smaller value for the $\mathrm{C}_{d}$. The effect of petal direction has the greatest influence on the petals with medium bending angle and medium integrity ratio as the flow creates a jet closest in size to the projected orifice size.

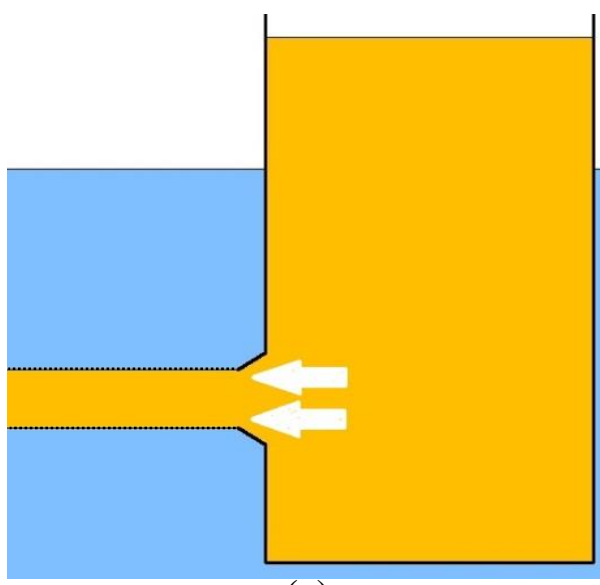

(a)

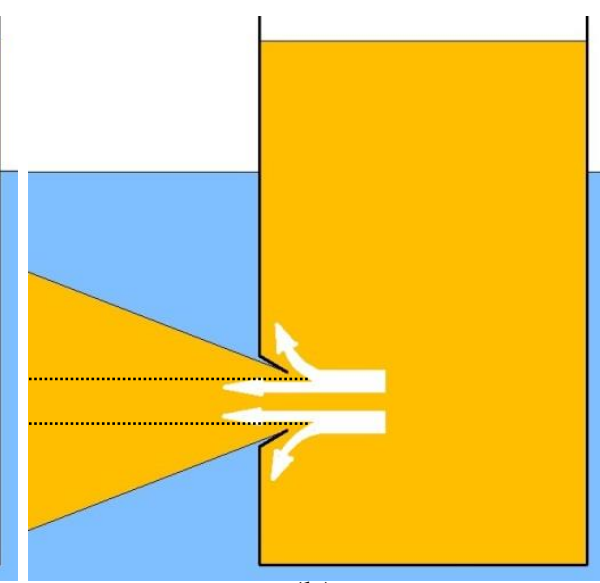

(b)

Figure 15 The oil flow with (a) outward facing petals (b) inward facing petals Since the oil-water interaction is a complicated process rather than a fluid simply discharging into another fluid, the $C_{d}$ cannot be calculated by using Equation 10. The water levels are analysed instead to investigate the effect of different petal properties. The influx of the water into the compartment is similar to that of oil. For each of the scenarios it can be seen that there is a rapid influx of water where the rate decreases throughout the process. From Figures 16-18 it can be observed that in general the influx of water flooding rated for orifices with petals are smaller than those without, 0-None. Figures 16 and 17 show how the flooding rate decreases with the bending angle and they also show that it takes longer for the petals with small angles to reach the second and third period of flooding. This may be due to the obstruction effect of the petals getting in the way of the flow slowing the flooding.

The behaviour elicited from changing the integrity ratio is similar, if less clear, than those seen in bending angle, as can be seen for Figure 18, where the fuller petals have a slower influx rate than those with less petalling. The effect of the integrity is most for the low bending angle, $40^{\circ}$, and least for the high bending angle, $80^{\circ}$. The change in integrity ratio also affects the point at which the third period of flooding is achieved. 


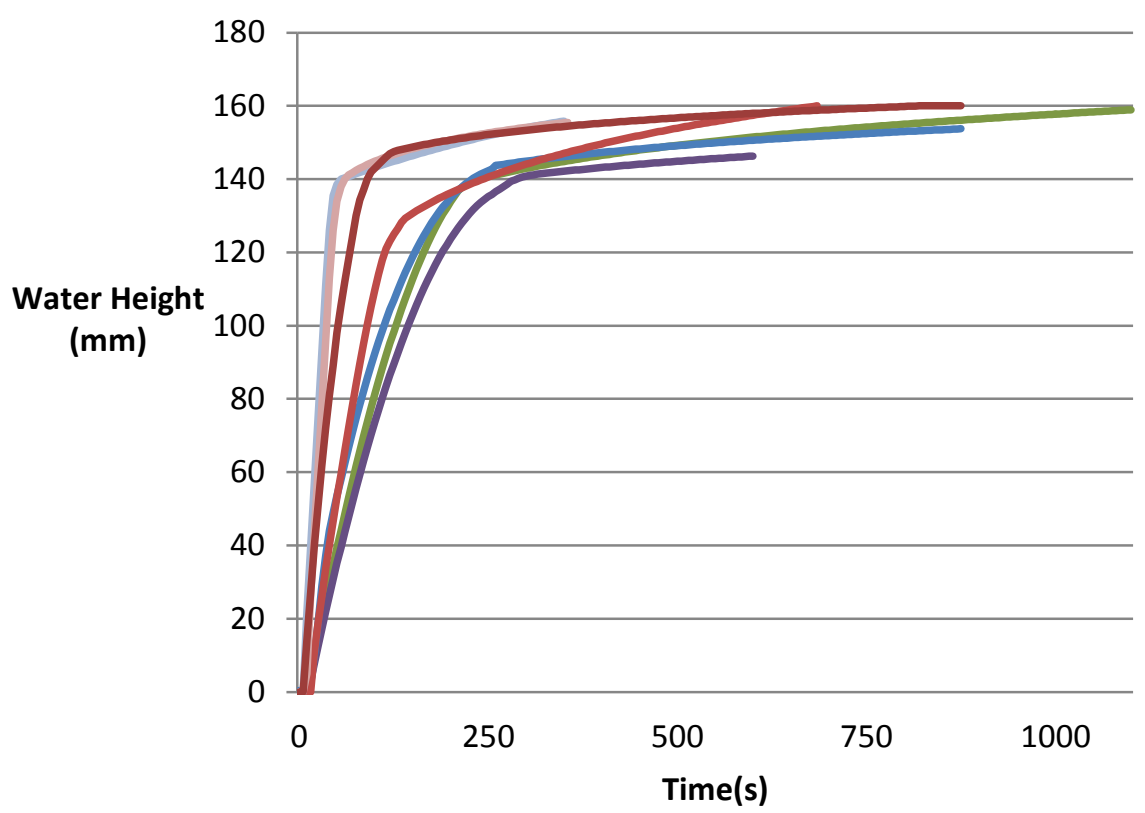

Figure 16 Fluid outflow for fully petalled orifices

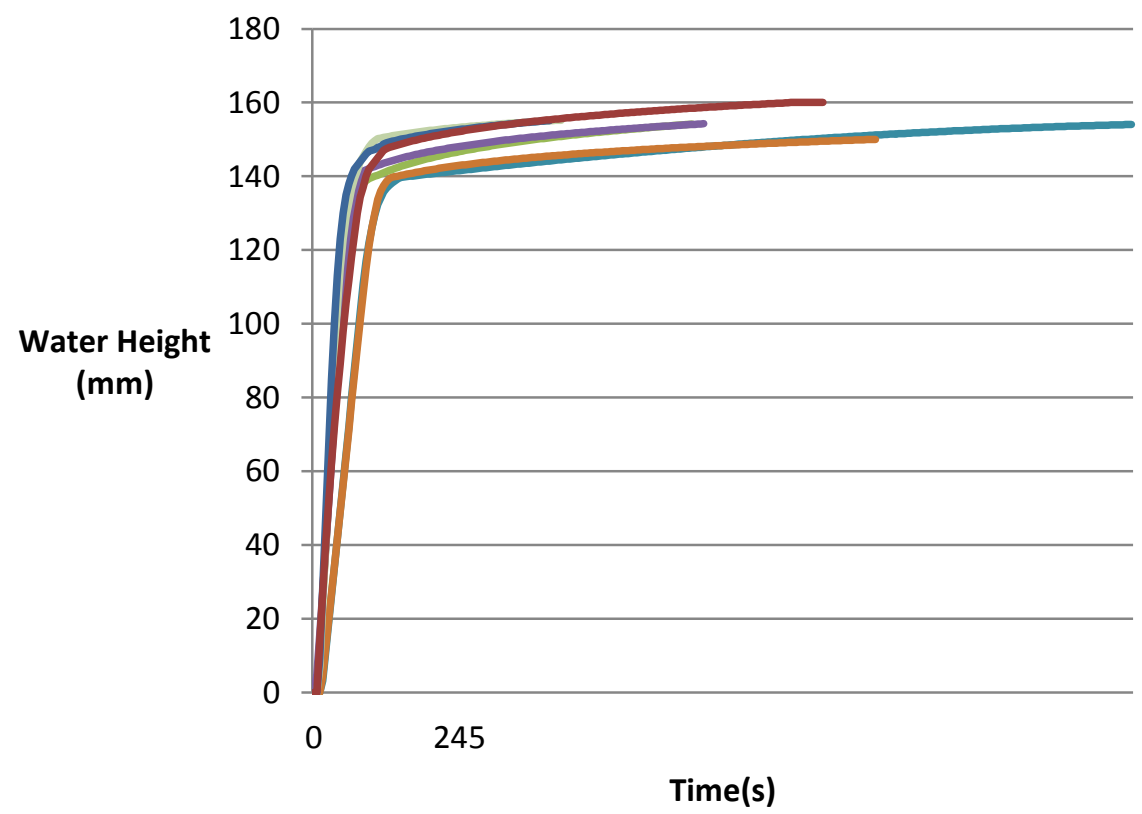

Figure 17 Fluid outflow for half petalled orifices 40-full-in

$\longrightarrow$ 40-full-out

60-full-in

60-full-out

80-full-in

80-full-out

0-None

40-half-in

40-half-out

60-half-in

60-half-out

80-half-in

80-half-out

0-None 


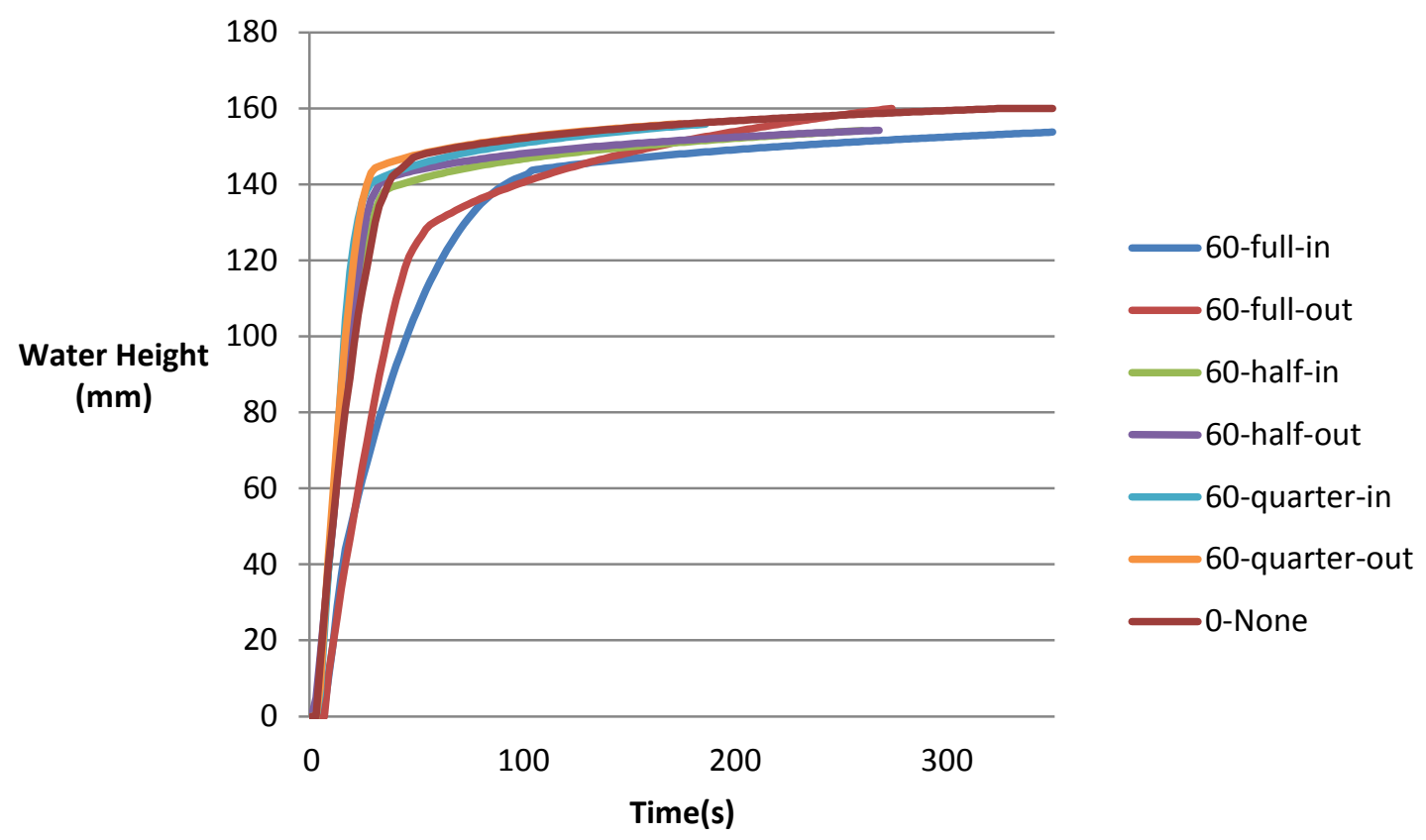

Figure 18 Fluid outflow for $60^{\circ}$ petalled orifice

Figure 18 highlights that the height of the start of the third period is affected by the change of integrity ratio. For the $60^{\circ}$ case the full integrity ratio petals enters the third period when the water level reaches $130 \mathrm{~mm}$. The case with half integrity enters the third period when the water level reaches about $140 \mathrm{~mm}$. For the case of quarter integrity ratio, it requires water level of $145 \mathrm{~mm}$ to enter the third period. Figure 19 illustrates the behaviour showing how the petals with higher integrity ratio lower the 'effective height' of the upper edge of orifice. This trend is more significant for the outward facing petals than for those facing inwards. The lip of the petal forces the oil to move further horizontally around the edge of the petal. 


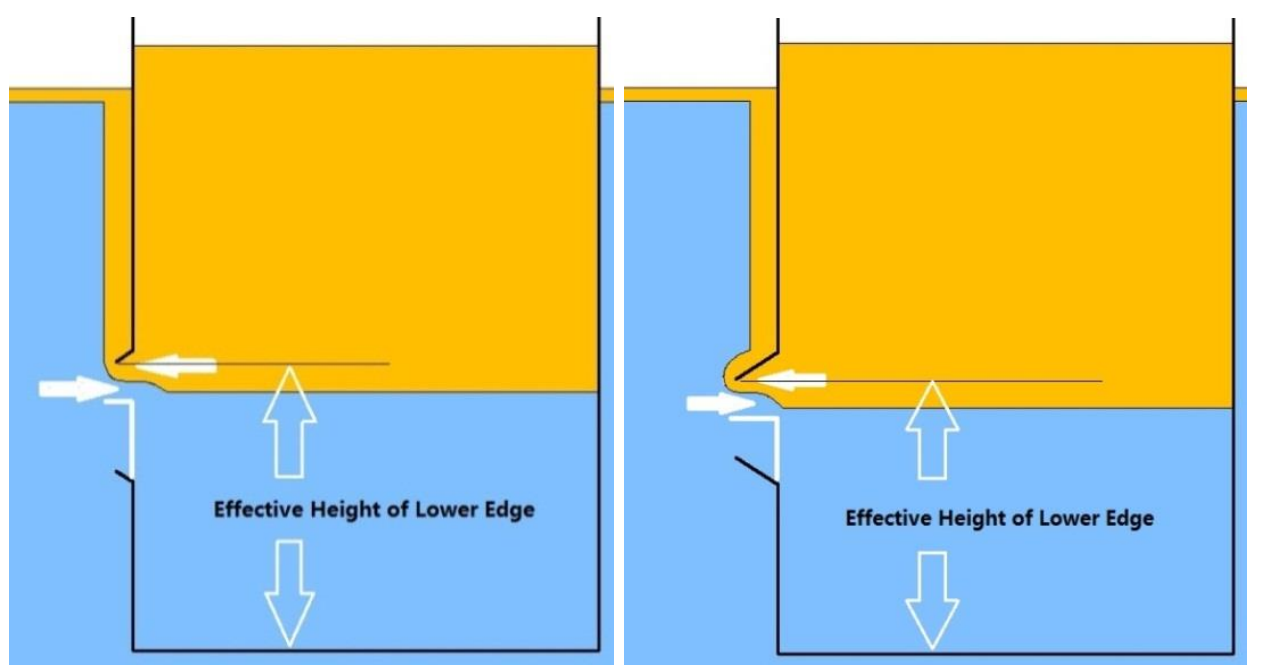

Figure 19 Effective height of lower edge (a) Small integrity (b) Large integrity

The case of the water influx shows a minimal difference between the cases with inward and outward facing petals. The oil outflow rate is always equal to the water inflow rate at any time during the water influx period. Assuming that the outward facing petals enhance the oil outflow, the water inflow then should be obstructed by them but this will also occur the other way round. Thus the effects of enhancement and obstruction offset each other due to the equal flow rate of inflow and outflow.

\subsection{Case 2 (Initial oil level lower than water level)}

The second case is for the condition where the level of the oil in the compartment starts lower than the water outside. This is a common condition for compartments which contain limited oil, such as fuel tanks, or where the compartment is submerged. Before the test starts, the water pressure at the orifice position is much larger than the oil pressure on the other side. The plug is then removed and the water can flood directly into the compartment. The oil is lifted above the in-flooding water until the pressures balance. The oil and water will exchange until inner pressure is equal to the outer one. This process is extremely rapid compared to oil flooding out of the compartment. The $C_{d}$ values were calculated before the water level reaches the orifice because after this point the water will be exchanging with the oil and the assumptions required for the simplified approach are no longer true. In this case the initial oil level in the compartment is chosen at $200 \mathrm{~mm}$ and the initial immersion depth is chosen at $400 \mathrm{~mm}$. At the beginning of flooding, the water flows into only one medium which is oil. The $C_{d}$ can be obtained by applying Equation 11 . However, as the inside water 
level rises, the fluid medium behind the orifice will becomes a mixture of oil and water and Equation 11 cannot be applied. Therefore, all of the water level data used to calculate $C_{d}$ is below the lower edge of the orifice at, $90 \mathrm{~mm}$.

\subsubsection{Flat sided orifices}

Figure 20 shows results for 5 damaged shapes, 3 circles with diameters of $69.81 \mathrm{~mm}$, $51.52 \mathrm{~mm}$ and $30 \mathrm{~mm}$ and 2 squares with sides of $70 \mathrm{~mm}$ and $45.66 \mathrm{~mm}$. From the results shown in Figure 20, the larger the orifice area the faster the water flooding will be but the shape once again makes little difference to the time period in which the water floods into the compartment with the area playing a much larger role in this rate

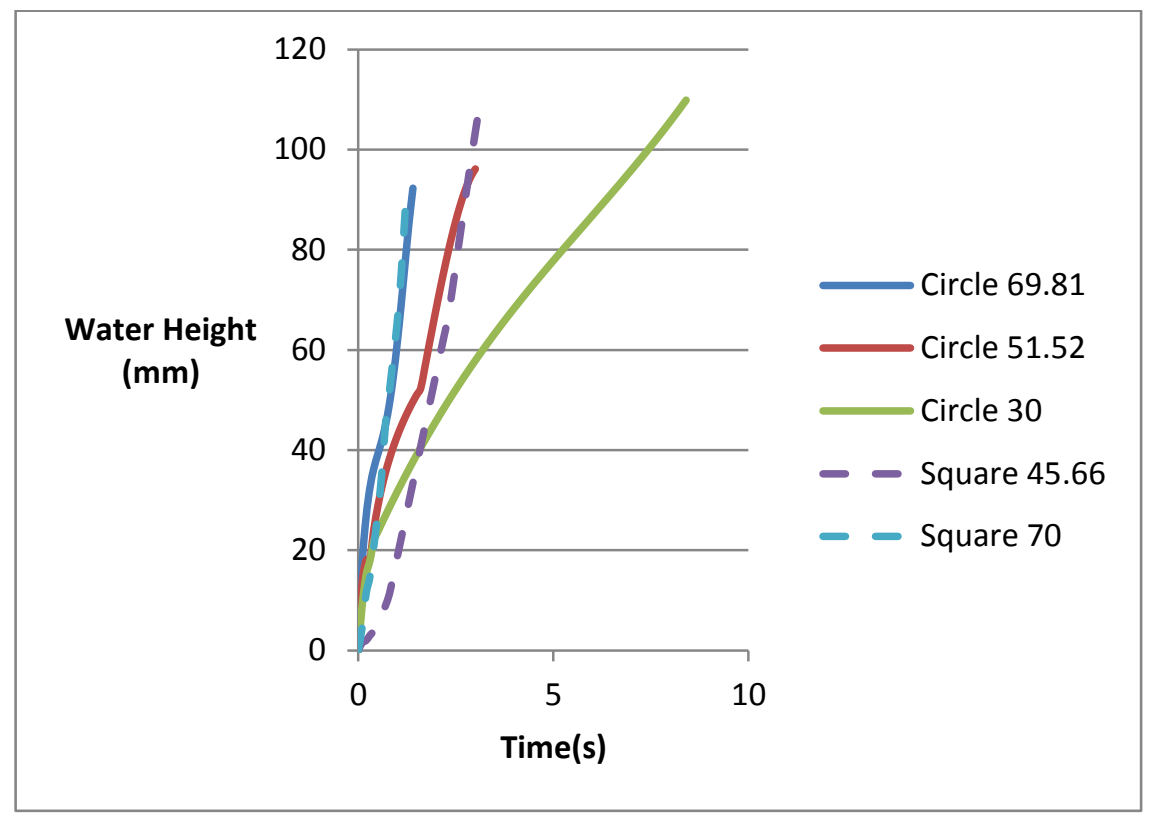

Figure 20 Water height for oil level initially lower than water

Table 6 Flooding period of $C_{d}$ for circular and square orifices

\begin{tabular}{|c|c|c|c|}
\hline \multicolumn{4}{|c|}{ Circle } \\
\hline Diameter $(\mathrm{mm})$ & 69.81 & 51.52 & 30 \\
\hline Area $\left(\mathrm{mm}^{\wedge} 2\right)$ & 3828 & 2084.8 & 707 \\
\hline$C_{d}$ of leaking & 0.71 & 0.65 & 0.61 \\
\hline$C_{d}$ of flooding & 0.40 & 0.32 & 0.31 \\
\hline Leaking Time (s) & 4.3 & 6.9 & 17.8 \\
\hline Flooding Time (s) & 1.3 & 2.6 & 8.3 \\
\hline
\end{tabular}




\begin{tabular}{|c|c|c|c|}
\hline & & & \\
\hline \multicolumn{3}{|c|}{ Square } \\
\hline Side Length (mm) & 70 & 45.66 & \\
\hline Area (mm^2) & 4900 & 2084.8 & \\
\hline$C_{d}$ of leaking & 0.69 & 0.66 & \\
\hline$C_{d}$ of flooding & 0.51 & 0.49 & \\
\hline Leaking Time (s) & 3.2 & 6.9 & \\
\hline Flooding Time (s) & 1.1 & 2.8 & \\
\hline
\end{tabular}

Table 6 shows the results for the $C_{d}$ values and time periods for the oil flooding out of and the water flooding into the compartment for each shape tested. It can be seen that the shape has a large effect on both the $C_{d}$ and the period. Comparing the leaking of the oil out of the compartment and the water into oil it can be seen that the oil takes much longer to flood out than the water flooding in but this is because there was more oil to flood out however, the trends are similar to those of the leaking time period. The $C_{d}$ value is smaller for the oil starting lower than the water consistent with the longer time period for the water to flood in.

\subsubsection{Petalled Orifices}

Table 7 Flooding period and $C_{d}$ for petalled orifices

\begin{tabular}{|l|c|c|}
\hline Petal No. & Flooding period & $C_{d}$ \\
\hline 0-None & 3.8 & 0.82 \\
\hline 60-Full outward facing & 5.2 & 1.29 \\
\hline 60-Full inward facing & 4.8 & 1.12 \\
\hline
\end{tabular}

The results of flooding period and $C_{d}$ are shown in Table 7. The trends for the initial oil level below the waterline are similar to the ones where this initial level is above the petals in terms of the flooding period. The flooding time for the petals is longer than without petals. The $\mathrm{C}_{d}$ value is much higher for the oil starting below the waterline with the values going higher than 1 . 


\section{Discussion}

In the examination of ship damage it is important to determine the influence of modelling a damaged orifice in 3D where the edge of the orifice will likely have some petals. Li et al. (2013) provided some experimental results on the effects of petalling on orifice flows showing that its addition, and the direction in which they were facing, made a considerable impact on the flow. This study used a projected area of the petals onto the orifice plane to compare petalled and smooth orifices and this same approach is used in Table 8 to show the comparison between flat sided and petalled orifices in situations where there is oil.

Table 8 Comparison of flat sided and petalled orifices

\begin{tabular}{|l|c|c|c|c|c|c|c|c|}
\hline \multicolumn{3}{|c|}{ Area $3828 \mathrm{~mm}^{2}$} & \multicolumn{3}{c|}{ Area $2450 \mathrm{~mm}^{2}$} & \multicolumn{3}{c|}{ Area $2085 \mathrm{~mm}^{2}$} \\
\hline Shape & $C_{d}$ & $\begin{array}{c}\text { Flooding } \\
\text { Period }\end{array}$ & Shape & $C_{d}$ & $\begin{array}{c}\text { Flooding } \\
\text { Period }\end{array}$ & Shape & $C_{d}$ & $\begin{array}{c}\text { Flooding } \\
\text { Period }\end{array}$ \\
\hline Square & 0.73 & 3.9 & Square & 0.62 & 5.6 & Square & 0.66 & 6.9 \\
\hline Circle & 0.71 & 4.3 & Circle & 0.65 & 6.5 & Circle & 0.65 & 6.9 \\
\hline $\begin{array}{l}\text { Quarter } \\
\text { in 60 }\end{array}$ & 0.60 & 4.2 & $\begin{array}{c}\text { Full in } \\
60^{\circ}\end{array}$ & 0.69 & 5.8 & $\begin{array}{c}\text { Half in } \\
40^{\circ}\end{array}$ & 0.59 & 7.9 \\
\hline $\begin{array}{l}\text { Quarter } \\
\text { out 60 }\end{array}$ & 0.78 & 3.5 & $\begin{array}{c}\text { Full out } \\
60^{\circ}\end{array}$ & 0.74 & 5.2 & Half & 0.70 & 7.2 \\
out $40^{\circ}$ & & & \\
\hline
\end{tabular}

For the three different areas the $C_{d}$ values of the orifices with petals facing inwards are smaller on average than those with flat edges and the outward facing petals have a larger $C_{d}$. In each case the flat edged results show similar values to each other for the square and circular orifices, reflecting that shape was not an important factor whether the water was flooding into or out of the compartment, as shown previously. Among all the factors such as shape, area, direction and petalling, it is petalling that is the most significant and for the petals the direction is the most influential characteristic. A trend can be seen whereby the flooding rate decreases with the bending angle and for these petals with smaller angles it takes longer to reach the second and third periods of flooding. This may also be due to the obstruction created by the petals where both the inflow of water and the outflow of oil are obstructed. For petals with low bending angles, $40^{\circ}$, the change of integrity ratio had the greatest impact. In terms of the 
integrity, full petals significantly delay the process of oil-water interchange and the first period becomes short under the effect of full integrity. When water is flooding into the compartment the $C_{d}$ value becomes lower with petals and the flow time increased.

When observing the oil jet, taking the 60-Full inward facing petals as an example, it retains a strong thin straight jet in the centre which diverges away from the projected area at the edges. This is because the inward facing petals with a medium bending angle serve as a guide. However, the upper/lower border of the jet is misaligned as the petals 'block' the oil flow and the velocity of the jet is reduced. Jets with a low velocity are therefore more likely to become weak and unstable. For a square orifice with flat edges the oil jet is strong and compact. The upper and lower boundaries of the oil jet are close to being straight lined but the edges are also slightly divergent and the upper/lower borders of the jet are not smooth. The slight divergence at the end and the minor perturbation on the jet boundary indicate that this jet is unstable to some extent. By contrast, the oil jet in the test with orifice plate 80-Half outward facing is more compact. The upper and lower boundaries of the oil jet are smoother and intact compared with the jet with no petals. The jet is stronger and more stable. This is because the $80^{\circ}$ petal bending angle is aligned almost to the same direction of the jet velocity. As a result, an incomplete pipe is generated and the jet is enhanced. For the 60-Full outward facing case, the oil jet is disturbed by the petals on the orifice plate. The jet is still strong and fast since the upper/lower border of the central thin jet are quite smooth and intact.

Because of the quasi-static assumption, a significant factor in all of the analyses performed is the period by which the flooding period is taken for the $C_{d}$. It is decided to use fluid volume change to determine the time period as adopted in this paper since it is observed that the $C_{d}$ changes significantly throughout the flooding and the point at which this calculation is performed gave significantly different trends and values. This is similar to the case of Li et al. (2013) who showed that the area for the petalling significantly affected the value of $C_{d}$ and, more significantly the trend. Furthermore, this makes comparison between studies difficult and causes problems in getting definitive trends for the experimental results. Further investigations will therefore be 
required to investigate how the $C_{d}$ changes over time and to draw conclusions over how to calculate its value more fairly between experiments and different applications to allow easier comparisons.

\section{Conclusions}

When oil spills occur they can have a detrimental impact to the surrounding environment which is costly to clean up and they can also reduce the stability of a vessel. Characterising these spills is therefore important to provide guidance to salvage experts and crews. To investigate the phenomenon of the flow of oil and water, experiments have been performed on a rectangular compartment with vegetable oil to simulate oil spill scenarios. Testing was performed on test panels with 14 different orifices with no petalling and 15 groups with different petal bending angles, integrity ratios and petal directions. The experiments show that the flow can be categorised in different stages to that of water entering an empty compartment as first the oil flows out of the compartment rapidly; this flow then slows down until an exchange of water entering the compartment occurs and finally the level of oil and water stabilises and limited change can then be seen. The experiments have detected a number of interesting new trends. It can be seen that the $C_{d}$ value for the same shape and area of orifice is larger for an empty compartment than for oil leaking into water. They show that, whilst the trends for the $C_{d}$ are the same for water flooding into an empty compartment and oil leaking into water, the $C_{d}$ for water filled compartments is smaller than that of oil leaking. In both cases petalling has been shown to be the most important variable affecting the $C_{d}$ of flows both into an empty or oil containing compartment.

\section{References:}

Balakhrisna, T. Ghosh, S. Da, G. and Das, P.K., 2010, Oil-water flows through sudden contraction and expansion in a horizontal pipe - Phase distribution and pressure drop, International Journal of Multiphase Flow, vol.36, pp.13-24

Bazsó, C. and Hős, C.J., 2013, An experimental study on the stability of a direct spring loaded poppet relief valve, Journal of Fluids and Structures, Vol. 42, pp. 456465

Caleyron, F. Combescure, A. Faucher, V. and Potapov, S., 2013, SPH modeling of fluid-solid interaction for dynamic failure analysis of fluid-filled thin shells, Journal of Fluids and Structures, Vol. 39, pp. 126-153 
Chang, B.-C. and Blume, P., 1998, Survivability of Damaged Ro-Ro Passenger Vessels, Schiffstechnik - Ship Technology Research, Vol.45, pp. 105-117.

Dand, I., 1988, Hydrodynamic Aspects of the Sinking of the Ferry Herald of Ferry Enterprise, Transactions of Royal Institute of Naval Architecture, Vol. 130, pp.145167.

Dodge, F.T. Bowles, E.B. Mann, J.E. and White, R.E., 1980, Experimental verification and revision of the venting rate model of the Hazardous Assessment Computer System and the vulnerability model. Groton, Connecticut: United States Coast Guard, Office of Research and Development. Final Report CG-D-63-80. pp. 207.

Dodge, F.T and E.B. Bowles, 1982, Draining of tanks with submerged outlets or without vacuum-relief, Journal of Fluids Engineering, vol. 104, pp. 67-71.

Eghtesad, A. Shafiei, A.R. and Mahzoon, M., 2012, A new fluid--solid interface algorithm for simulating fluid structure problems in FGM plates, Journal of Fluids and Structures, Vol. 30, pp. 141-158

Fingas, M. and Charles, J., 2001, The basics of oil spill cleanup, 2nd ed. Chapter 1, Boca Raton (FL): Lewis Publishers.

Gao, Z. Gao, Q. and Vassalos, D. (2011), Numerical simulation of flooding of a damaged ship, Ocean Engineering, vol. 38, pp.1649-1662.

Hearn, G. E. Lafforgue, D. Perdriset, E. and Saydan, D., 2008, The hydrodynamic and dynamic motion analysis of a damaged ship, Transactions of Royal Institute of Naval Architects, vol. 150, pp.75-99.

Journee, J. Verneer, H. and Vredeveldt, A.W., 1997, Systematic Model Experiments of Flooding of Two Ro-Ro Vessels, Proceedings of the 6th International Conference on Stability of Ships and Ocean Vehicles, Varna, Bulgaria, 22-27. September, 1997.

Karafiath, G., 1992, Accidental Oil Spill Due to Grounding, In: Summary of Model Test Results. SHD-1386-02.1992.

Karafiath, G. and Bell, R.M., 1992, Oil Spill Model Tests on a Mid Deck Tanker and on a Double Hull Tanker Configuration. DTRC/SHD-1386-01.

Lee, D. Hong, S. Y. and Lee, G.-J., 2007, Theoretical and Experimental Study on Dynamic Behaviour of a Damaged Ship in Waves, Ocean Engineering, Vol.34, pp.21-31.

Li, Y. A. J. Sobey and M. Tan. (2013) Investigation into the Effects of Petalling on Coefficient of Discharge during Compartment Flooding, Journal of Fluids and Structures, Vol. 45, pp.66-78.

Massey B.S., 1968, Mechanics of fluids, London: D. Van Nostrand Company Ltd.

Mohammad T.T. Jørgen A. and Bernt J. L., 2010, Analytical and numerical modelling of oil spill from a side tank with collision damage. Ships and Offshore Structures, Vol. 7, No. 1, pp. 73-86 
Nie F., 2013, CFD simulation of oil spillage from damaged ships with ANSYS FLUENT. Master dissertation, University of Southampton.

Patrick, B., 2010, Oil spills: Legacy of the Torrey Canyon. Retrieved, Jan 2, 2013 from http://www.guardian.co.uk/environment/2010/jun/24/torrey-canyon-oil-sspildeepwater-bp

Ruponen, P., 2006, Model Tests for the Progressive Flooding of a Boxed-Shaped Barge, Helsinki University of Technology, Ship Laboratory, Report M-292, pp.7-23

Ruponen, P., 2007, Progressive flooding of a damaged passenger ship, PhD Thesis, Helsinki University of Technology, Finland.

Ruponen, P. Sundell,T. and Larmela, M., (2007), Validation of a simulation method for progressive flooding, International Shipbuilding Progress, 54(4), 305-321.

Ruponen, P. Kurvinen,P. Saisto,I. and Harras, J., (2010), Experimental and numerical study on progressive flooding in full-scale, Transactions of Royal Institution of Naval Architects, International Journal Maritime Engineering, A-197-A-207

Santos, T. A. and Guedes Soares, C., 2008, Study of damaged ship motions taking into account floodwater dynamics. Journal of Marine Science and Technology, 12:291-307.

Sen, P. and Konstantinidis, C., 1987, A Time Simulation Approach to the Assessment of Damage Survivability of Ro/Ro Cargo Ships, Transactions of Society of Naval Architects and Marine Engineers, SNAME, Vol. 95, pp. 337-355.

Simecek-Beatty, D.A. Lehr, W. J. and Lankford, J.L., 1997, Leaking Tankers: How much oil was spilled?, In Proceedings of ,the Arctic Marine Oilspill Program Technical Seminar, Vancouver, B.C. Canada. 2:841- 851.

Simecek-Beatty, D.A. Lehr, W. J. and Lankford, J.L., 2001, Leaking Tank Experiments with Orimulsion ${ }^{\mathrm{TM}}$ and Canola Oil. NOAA Technical Memorandum NOS $O R \& R$ 6. pp. 2-28.

Smith, D. and Walker, W. J. (1923) Orifice flow. Journal of the Institute of Mechanical Engineers (Great Britain), January 1923.

Smith, T.W.P., 2009, Wave Loading on Damaged ships, Thesis of the degree of Doctor of Philosophy in the subject of Naval Architecture, University College London.

Spouge, J. R., 1986, The Technical Investigation of the Sinking of the Ro-Ro Ferry European Gateway, Transactions of Royal Institute of Naval Architects, RINA, Vol. 128 , pp. $49-72$

Tan, C. Dai, W. Yeung, H. and Dong, F., 2014, A Kalman estimation based oil-water two-phase flow measurement with CRCC, International Journal of Multiphase Flow, In Press

Tavakoli, M.T. Amdahl, J., Ashrafian, A., and Leira, B., 2008. Analytical Predictions of Oil Spill from Grounded Cargo Tankers, In: Proceedings of the ASME $27^{\text {th }}$ International Conference on Offshore Mechanics and Arctic Engineering, Estoril, Portugal. 
Tavakoli, M.T. Amdahl, J. and Leira, B., 2009, Investigation of Interaction Between Oil Spills and Hydrostatic Changes, In: Proceedings of the ASME 28th International Conference on Offshore Mechanics and Arctic Engineering, USA.

Tavakoli, M.T. Amdahl, J. and Leira, B., 2011, Experimental investigation of oil leakage from damaged ships due to collision and grounding, Ocean Engineering, vol. 38, pp. 1894-1907.

Turan, O. and Vassalos, D., 1994, Dynamic Stability Assessment of Damaged Passenger Ships, Transactions of Royal Institute of Naval Architects, RINA, Vol. 136, pp. 79-104.

Vassalos, D. and Letizia, L., 1998, Characterisation of Flooding Process of Damaged Ro-Ro Vessel, International Journal of Offshore and Polar Engineering, Vol. 8, No. 3, September 1998.

Vassalos, D. Turan, O., 1994. A Realistic Approach to Assessing the Damage Survivability of Passenger Ships, Transactions of Society of Naval Architects and Marine Engineer, SNAME, Vol. 102, pp. 367-394

Vredeveldt, A.W. Journée, J.M.J., Roll Motion of Ships due to Sudden Water Ingress, Calculations and Experiments, RINA'91, International Conference on Ro-Ro Safety and Vulnerability the Way Ahead, London, United Kingdom, 17-19. April 1991, Vol. I.

Wood, C.D. Hudson, D.A. and Tan, M., 2010, CFD Simulation of Orifice Flow for the Flooding of Damaged Ships, NuTTS 2010.

Wood, C.D., 2013, Compartment Flooding and Motions of Damaged Ships, EngD Thesis, University of Southampton

Xia, J. Jensen, J.J. and Pedersen P.T., 1999, A Dynamic Model for Roll Motion of Ships Due to Flooding, Schiffstechnik - Ship Technology Research, vol. 46, pp. 208216.

Zaraphonitis, G. Papanikolaou, A.D. and Spanos, D. On a 3-D mathematical model of the damage stability of ships in waves, Proceedings of the 6th International Conference on Stability of Ships and Ocean Vehicles (STAB'97), Varna, Bulgaria, September 1997, pp.233-244 